\title{
La comunicación de crisis en la administración pública española: análisis de evidencia empírica
}

\section{Crisis Communication in the Spanish Public Administration: Organizational Culture and Empirical Evidence}

\author{
Ismael Crespo \\ Universidad de Murcia \\ icrespo@um.es \\ Antonio Garrido \\ Universidad de Murcia \\ agarrido@um.es \\ Rosa M. ${ }^{\text {a }}$ Medina \\ Universidad de Murcia \\ rosamaria.medina@um.es
}

\section{RESUMEN}

Catástrofes, terremotos, pandemias, enfermedades epidémicas, emergencias y la alteración de los servicios básicos son sólo algunos de los acontecimientos impredecibles que muestran de qué manera las crisis pueden desarrollarse con gran rapidez y la importancia que tiene para los gobiernos y las administraciones públicas gestionar efectivamente su comunicación de crisis.

La experiencia de crisis nacionales (la política detrás de la crisis del Ébola, el terremoto de Lorca, el movimiento vecinal de Gamonal en Burgos, la huelga no autorizada de los controladores aéreos en 2010 o el accidente de tren en Angrois) muestran que la comunicación efectiva requiere una extensa preparación y este artículo presenta un trabajo empírico sobre la comunicación de crisis de las administraciones públicas en España.

El objetivo de esta investigación es describir el estado de la práctica de la comunicación de crisis en la administración del Estado, comunidades autónomas y municipios, con el apoyo en las percepciones de sus trabajadores. Para lograrlo, realizamos un estudio a través de encuesta con referencias a casos de crisis gestionados por la Administración Pública española.

\section{PALABRAS CLAVE}

Administración pública, comunicación de crisis, política de comunicación.

\section{ABSTRACT}

Catastrophes, earthquakes, pandemics, epidemic diseases, emergencies and the disruption of basic services are just a few of the unpredictable events which show how rapidly crises can develop and how important it is for governments and public administrations to manage their crisis communication effectively.

Experience from national crises (the politics behind the Ebola crisis, Lorca earthquake, the neighborhood movement of Gamonal in Burgos, the unauthorized strike by air traffic controllers in 2010 or the train crash in Angrois) shows that effective communication requires extensive preparation and this article presents one of the first empirical works on the crisis communication of public administrations in Spain. 
This research aims to describe the state of the practice of crisis communication in the different levels of the Spanish Public Administration (State, Autonomous Communities and municipalities), based on the perceptions of its workers. To achieve this objective, a poll study was developed, with references to crisis cases managed by the Spanish Public Administration.

\section{KEYWORDS}

Public administration, crisis communication, political communication.

\section{SUMARIO}

1. INTRODUCCIÓN. 2. SINGULARIDADES DE LA COMUNICACIÓN DE CRISIS. 3. DISEÑO DE LA INVESTIGACIÓN. 4. GESTIÓN DE LA COMUNICACIÓN DE CRISIS EN LAS ADMINISTRACIONES PÚBLICAS. 5. LA FASE DE PREVENCIÓN O PRE-CRISIS. 5.1. AUDITORÍAS DE CRISIS. 5.2. IDENTIFICACIÓN DE AMENAZAS PARA LA ORGANIZACIÓN. 5.3. SIMULACROS DE CRISIS. 5.4. MANUAL DE CRISIS. 6. LA FASE DE CRISIS. 6.1. EL COMITÉ DE CRISIS. 6.2. LA FIGURA DEL PORTAVOZ. 6.3. RELACIONES CON LOS MEDIOS. 6.4. EL MENSAJE: ELEMENTOS Y HERRAMIENTAS. 7. POST-CRISIS: EVALUACIÓN Y CULTURA DE CRISIS. 8. DISCUSIÓN DE LOS RESULTADOS. ANEXO 1. FICHA TÉCNICA DE LA ENCUESTA. BIBLIOGRAFÍA.

\section{INTRODUCCIÓN}

El análisis de «casos» de comunicación de crisis que han inundado las páginas de los mass media, ya sean en forma de crisis políticas, escándalos de corrupción, crisis empresariales o económicas, de mercados y de empresas, crisis alimentarias, crisis sanitarias, crisis terroristas, crisis provocadas por una catástrofe natural o un accidente, evidencian su amplia variedad tipológica. El contexto donde la crisis se produce, el momento en que se desencadena, las políticas públicas que se adoptan y la estrategia de su comunicación pueden ser algunos elementos que expliquen sus diferencias. En el caso de las crisis políticas y administrativas, la reciente crisis del «Ébola» en España y en otros países reabrió el debate sobre la adecuada comunicación de este tipo de sucesos. Con anterioridad, en nuestro país, se habían desarrollado numerosas crisis que habían evidenciado los problemas y las dificultades de las distintas administraciones públicas implicadas en su gestión y resolución, y especialmente de los responsables del traslado a los ciudadanos de la información y la comunicación, para actuar eficazmente durante el desarrollo de las mismas: crisis ambientales, en los casos «Prestige» o «Aznalcóllar»; crisis de salud pública, como las epidemias de «gripe A» o la mencionada del «Ébola»; crisis de seguridad alimentaria, como la de las «vacas locas»; siniestros, como el descarrilamiento del tren Alvia en Angrois, el accidente del metro de Valencia, el Madrid-Arena o la tragedia aérea del "Yakovlev»; crisis de seguridad, derivadas de atentados terroristas; distintas catástrofes naturales, como el terremoto de Lorca, inundaciones, etc. (Cases, 2010; Gervás y Hernández-Aguado, 2009; Losada, 2010; Losada Maestre, 2016; Mercado y Chávez, 2016; Vanaclocha, Natera y García Sánchez, 2007; Vanaclocha, García Sánchez y Natera, 2010).

Sin embargo, la labor investigadora en este ámbito no está tan desarrollada en España como en otros países de nuestro entorno (Bohn, 2015; Coombs y Holladay, 2010; Fearn-Banks, 2007; George y Pratt, 2012; Heat y O'Hair, 2009; Islas y Hernández, 2013; Olsson, 2014; Rosenthal, Boin y Comfort, 2001; Rosental, Charles y t'Hart, 1989). Como bien ha señalado José Antonio Olmeda, pese a que «la gestión de crisis se ha convertido en una característica definitoria de la gobernación contemporánea», según han reconocido recientemente numerosos expertos, «tampoco las probabilidades de estudio desde la ciencia de la administración parecen muy favorables actualmente en nuestro país, a pesar de su relevancia para nuestra disciplina» (Olmeda, 2010: 1059).

Los episodios de crisis provocan ansiedad, preocupación y urgencia entre los gestores públicos, angustia entre los ciudadanos que adoptan el rol de administrado, y estrés informativo en los medios de comunicación en su pugna por ofrecer la primicia informativa de los acontecimientos. La situación de dificultad que inaugura una crisis exige de los gestores públicos una solución rápida al conflicto a fin de recuperar el estado de normalidad previo a la eclosión de la emergencia. Por lo tanto, se necesita de un estrategia de comunicación que evite el impacto de la crisis o que minimice el daño y lo convierta en un activo positivo (Tuñez, 2005). De no producirse, se pueden ver abocados a una crisis de confianza en las instituciones y 
en sus máximos responsables. De ahí la conveniencia de incentivar las investigaciones avanzadas sobre comunicación de crisis en la Administración Pública y de establecer un repertorio de buenas prácticas y recomendaciones, desde una triple perspectiva: prevención, gestión y comunicación.

La gestión de una situación de crisis no se puede reducir solo al conjunto de medidas reactivas que se inauguran con la aparición de este fenómeno. Las administraciones, como organizaciones expuestas a sufrir una crisis, deben apostar por una gestión proactiva con una planificación de medidas de previsión y planificación, aun cuando nunca llegue a darse situaciones de este tipo (González Herrero, 1998). «La incapacidad de prever una crisis es uno de los principales factores para que estas se produzcan y se agraven. Cuanto mejor pueda usted prever todos los aspectos de una crisis, mejor podrá dominarla cuando ésta ocurra» (Mitroff y Pearsons, 1997:10).

González Herrero (1998: 38-39) define la gestión de comunicación de crisis como la «capacidad de una organización de reducir o prever los factores de riesgo e incertidumbre respecto al futuro, de forma que se capacite a la misma para asumir de manera rápida y eficaz las operaciones de comunicación necesarias que contribuyan a reducir o eliminar los efectos negativos que una crisis provoca sobre la imagen y reputación». Si la administración pública apuesta por la adecuada preparación y entrenamiento, definiendo los escenarios de crisis y los planes de prevención, puede lograr que los efectos de la crisis no sean tan graves como serían si la preparación fuera nula (Elizalde, 2009).

Para comenzar a evaluar este sector de actividad de las administraciones públicas, este artículo presenta la evidencia empírica y los principales resultados de una encuesta encargada por el INAP sobre el estado de la comunicación de crisis en las administraciones públicas españolas. Asimismo, se acompaña de las principales conclusiones de varios estudios de caso monográficos realizados sobre distintas crisis recientes (Ébola, terremoto de Lorca, Gamonal en Burgos, etc.) y de las entrevistas en profundidad con los responsables de comunicación en las mismas, que recientemente fueron presentados en unas Jornadas de Innovación Administrativa organizadas por el INAP.

\section{SINGULARIDADES DE LA COMUNICACIÓN DE CRISIS}

Para comenzar, conviene destacar algunas de las singularidades de este tipo de comunicación desde el punto de vista del contexto. Cuando una crisis se produce, el resto de tipos de comunicación (gubernamental, institucional, etc.) entran en estado de shock y quedan relegados a un segundo plano. En consecuencia, resulta conveniente que los responsables públicos y los miembros de los gabinetes de comunicación, reconozcan las singularidades y especificidades de este tipo de comunicación en comparación con los tipos más habituales de comunicación como la institucional o gubernamental.

Indudablemente, la comunicación electoral continúa siendo la más estudiada y analizada de todos los tipos de comunicación política. La comunicación electoral, una vez que se han definido tanto el mensaje central como los principales temas de campaña, intenta transmitir este mensaje por todos los medios posibles, tanto tradicionales como digitales, y de una manera repetitiva y reiterativa hasta que los votantes puedan identificar a los candidatos con un tema o con algunos temas concretos y determinados (Crespo et al., 2011; Mazzoleni, 2004; Maarek, 2011).

La comunicación institucional o gubernamental, aunque en ocasiones se distinguen ambas modalidades, supone la búsqueda de un consenso sobre la actuación del gobierno entre la opinión pública y el acuerdo sobre el conjunto de políticas públicas desarrolladas por las instituciones. Por ello se caracterizan, al igual que la comunicación electoral, por su lógica inclusiva, ya que se orientan a un destinatario colectivo formado por el conjunto de los ciudadanos. En muchos sentidos, puede decirse que la comunicación gubernamental se superpone, en los momentos de precampaña y campaña, con la comunicación electoral y comparte gran parte de sus características. Sin embargo, se diferencia de ésta, principalmente, porque pone más énfasis en la comunicación institucional que en la comunicación personalista, basada en el liderazgo, que es propia de la comunicación de campañas y porque no tiene un plazo de término tan rígido y concreto como la comunicación electoral, cuyo punto de llegada es el final de la campaña. La comunicación gubernamental, en ciertas ocasiones, suele confundirse con la comunicación institucional y con la comunicación de políticas públicas, aunque, en rigor, la comunicación de gobierno se refiere a la comunicación de instituciones públicas con función ejecutiva, lo que implica que la comunicación institucional constituye un tipo de comunicación más amplio y abarcador, puesto que incluye desde la comunicación de parlamentos y tribunales a la comunicación de instituciones simbólicas, como la jefatura del estado. 
En cambio, la comunicación de crisis debe enfrentarse a catástrofes, desórdenes, desviaciones y perturbaciones que generan una situación de incertidumbre y pretende, como su principal objetivo, impedir o limitar la escalada del fenómeno. Se trata de un tipo de comunicación definida por su carácter temporal, con unos límites bien definidos, y de corto plazo en su alcance; asimismo, es un tipo de comunicación muy autónoma, orientada a la gestión de la situación de emergencia, y poco relacionada o imbricada con los otros tipos de comunicación política. En este tipo de comunicación predominan los mensajes de significado directo, con ausencia de eslóganes o lemas, dado que el público destinatario de los mismos suele ser muy determinado, pese a que, en ocasiones, pueda verse afectada también el conjunto de la población con carácter general, por lo que el diseño de este tipo de comunicación debe priorizar una cierta «segmentación diferenciada» (Riorda, 2011).

TABLA 1. LA COMUNICACIÓN DE CRISIS COMPARADA CON OTROS TIPOS DE COMUNICACIÓN POLÍTICA

\begin{tabular}{|c|c|c|c|}
\hline & $\begin{array}{l}\text { COMUNICACIÓN DE } \\
\text { CRISIS }\end{array}$ & $\begin{array}{l}\text { COMUNICACIÓN } \\
\text { ELECTORAL }\end{array}$ & $\begin{array}{l}\text { COMUNICACIÓN } \\
\text { INSTITUCIONAL Y } \\
\text { GUBERNAMENTAL }\end{array}$ \\
\hline Objetivo & $\begin{array}{l}\text { Cerrar la crisis y limitar } \\
\text { sus efectos. Impedir la } \\
\text { escalada del proceso. }\end{array}$ & $\begin{array}{l}\text { Total: ganar las } \\
\text { elecciones. } \\
\text { Parcial: consolidar } \\
\text { posiciones y fidelizar al } \\
\text { electorado, avances en } \\
\text { votos y escaños. }\end{array}$ & $\begin{array}{l}\text { Generar consenso en la opinión } \\
\text { pública sobre la actuación del } \\
\text { gobierno. }\end{array}$ \\
\hline Destinatarios & $\begin{array}{l}\text { Lógica inclusiva compatible } \\
\text { con la segmentación } \\
\text { diferenciada en públicos. }\end{array}$ & $\begin{array}{l}\text { Lógica excluyente. Orientada } \\
\text { hacia un segmento o varios } \\
\text { del electorado. }\end{array}$ & $\begin{array}{l}\text { Lógica inclusiva: todos los } \\
\text { ciudadanos. }\end{array}$ \\
\hline Plazos & $\begin{array}{l}\text { Corto plazo: duración de } \\
\text { la crisis. La temporalidad } \\
\text { se asocia a su propia } \\
\text { definición. }\end{array}$ & $\begin{array}{l}\text { Corto plazo: precampaña y } \\
\text { campaña electoral. }\end{array}$ & $\begin{array}{l}\text { Medio y largo plazo: duración del } \\
\text { mandato del ejecutivo. }\end{array}$ \\
\hline $\begin{array}{l}\text { Antecedentes/ } \\
\text { consecuentes }\end{array}$ & $\begin{array}{l}\text { No siempre es posible } \\
\text { identificar con precisión su } \\
\text { comienzo pero sí su final. }\end{array}$ & $\begin{array}{l}\text { Tiene antecedentes (pues } \\
\text { la comunicación previa al } \\
\text { mandato es importante) pero } \\
\text { al tener un final determinado, } \\
\text { carece de consecuentes. }\end{array}$ & $\begin{array}{l}\text { Tiene antecedentes (pues la } \\
\text { comunicación previa al mandato } \\
\text { es importante) y consecuentes } \\
\text { (también la comunicación } \\
\text { posterior es relevante) }\end{array}$ \\
\hline Carácter & $\begin{array}{l}\text { Comunicación personalista, } \\
\text { de portavoces, y } \\
\text { excepcionalmente } \\
\text { institucionalista. }\end{array}$ & $\begin{array}{l}\text { Comunicación personalista, } \\
\text { de candidatos. }\end{array}$ & Comunicación institucionalista. \\
\hline Mensajes & $\begin{array}{l}\text { Mensajes de significado } \\
\text { directo y sin presencia de } \\
\text { eslóganes o lemas. }\end{array}$ & $\begin{array}{l}\text { Combina mensajes directos } \\
\text { y polisémicos. Uso de } \\
\text { varios eslóganes o lemas } \\
\text { simultáneamente. }\end{array}$ & $\begin{array}{l}\text { Combina mensajes directos y } \\
\text { polisémicos. Uso de un único } \\
\text { eslogan o lema principal. }\end{array}$ \\
\hline Costes & $\begin{array}{l}\text { Comunicación no } \\
\text { necesariamente costosa. }\end{array}$ & Comunicación muy costosa. & Comunicación costosa. \\
\hline $\begin{array}{l}\text { Relación } \\
\text { entre tipos }\end{array}$ & $\begin{array}{l}\text { Autónoma y poco } \\
\text { relacionada con las otras } \\
\text { formas de comunicación, } \\
\text { aunque puede } \\
\text { superponerse a ellas. }\end{array}$ & $\begin{array}{l}\text { Coexiste con la comunicación } \\
\text { gubernamental. En las } \\
\text { crisis puede confundirse } \\
\text { con la comunicación } \\
\text { gubernamental. }\end{array}$ & $\begin{array}{l}\text { En periodos electorales se } \\
\text { superpone con la comunicación } \\
\text { electoral. Cuando se superpone } \\
\text { a la comunicación de crisis suele } \\
\text { entrar en un paréntesis. }\end{array}$ \\
\hline
\end{tabular}




\section{DISEÑO DE LA INVESTIGACIÓN}

El trabajo de investigación presenta los datos empíricos obtenidos a partir de dos conjuntos de evidencias: una auditoría de $\operatorname{casos}^{1}$, a través de entrevistas en profundidad con sus protagonistas, y un cuestionario administrado a una muestra de distintas administraciones públicas en los distintos niveles de gobierno, abarcando a ministerios y consejerías, y a un gran número de municipios.

La auditoría de los casos resulta una experiencia única para poder conocer de primera mano la gestión de comunicación de crisis que afecta a las administraciones públicas. Los casos objeto de estudio son: el cierre del espacio aéreo en el año 2010, el terremoto de Lorca, el conflicto en el barrio burgalés de Gamonal y el contagio por el virus Ébola.

Para el diseño del cuestionario de la encuesta se implementó de forma inicial una metodología Delphi en la que participaron veintidós reconocidos expertos en el ámbito de la comunicación en situaciones de crisis. Este panel de expertos abarcaba tanto la vertiente académica como la profesional y cubría España y diferentes países de América Latina. El objetivo que se perseguía con la aplicación del Delphi era determinar de una forma ambiciosa las diferentes dimensiones que abarca la comunicación de crisis en las organizaciones públicas, así como generar una relación de categorías de análisis útiles para medir a través de la herramienta prevista. El producto obtenido fue depurado y completado por el equipo investigador, a partir de una profunda revisión de las principales referencias teóricas, así como de los protocolos y manuales de gestión más ambiciosos que fueron localizados. El resultado final fue un cuestionario de cincuenta y seis variables. La estructura del cuestionario único para todas las administraciones constaba de diversos filtros, a partir de las siguientes seis dimensiones generales de estudio:

- Departamento de comunicación de crisis.

- Fases de gestión en la comunicación de crisis.

- La figura del portavoz.

- Relaciones con los medios.

- Concienciación de importancia de crisis.

- El mensaje: elementos y herramientas.

El marco muestral definido para la aplicación de la encuesta consistió en los departamentos de comunicación de las administraciones públicas españolas, en los distintos niveles de gobierno: Ministerios, Comunidades Autónomas y Ayuntamientos. Se seleccionó una muestra inicial que abarcaba la totalidad de Ministerios, los responsables de comunicación de las Consejerías de Presidencia de las distintas Comunidades Autónomas, y una selección de 100 Ayuntamientos, determinada por una afijación proporcional al tamaño de la provincia. Los Ayuntamientos seleccionados en la muestra inicial cumplían con el criterio de ser los más grandes en población dentro de cada provincia, tratando así de incrementar la probabilidad de que dispusieran de protocolos para la gestión de la comunicación en situaciones de crisis. Finalmente, la muestra efectiva se conforma por tres unidades de la Administración General del Estado, diez de la Administración Autonómica, y sesenta y dos de la Administración Local o provincial. En total, son setenta y cinco unidades. Los resultados de la encuesta, expuestos de forma gráfica, muestran una disminución de casos en algunas variables por la «no respuesta» de las administraciones a determinadas preguntas, así como por la presencia de preguntas filtro en el cuestionario.

\section{GESTIÓN DE LA COMUNICACIÓN DE CRISIS EN LAS ADMINISTRACIONES PÚBLICAS}

Tan solo seis de cada diez organizaciones afrontan la comunicación en situaciones de crisis, de manera que tienen previsto su abordaje desde un departamento como se muestra en el Gráfico 1.

\footnotetext{
1 Las auditorías de casos de comunicación de crisis forman parte de un estudio elaborado para el INAP. Se realizaron cuatro estudios de caso con un análisis exhaustivo de la gestión de comunicación de una situación de crisis, medidas técnicas y estrategias de comunicación, la relación con los medios de comunicación y la evaluación de la gestión de la comunicación de crisis. Para cada uno de los casos, se realizaron entrevistas con los responsables del departamento de comunicación y con los responsables políticos en la gestión de las crisis. Las entrevistas se realizaron con un cuestionario semi-estructurado. Toda la información al respecto figura en el estudio financiado por el INAP.
} 
GRÁFICO 1. EXISTENCIA DE UN DEPARTAMENTO RESPONSABLE DE LA COMUNICACIÓN DE CRISIS ¿Existe en su organización algún departamento responsable de la gestión de comunicación en situaciones de crisis?

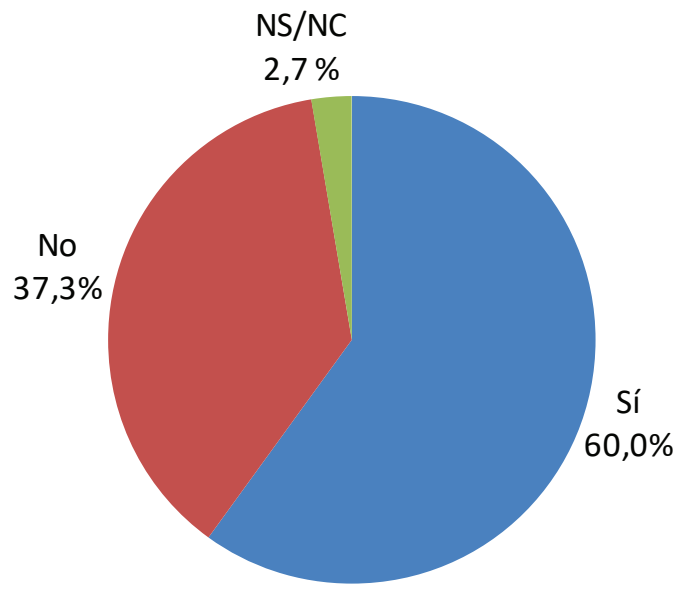

$\mathrm{N}: 75$ casos

Sin embargo, esta división departamental recae, en la práctica totalidad de los casos (88,9\%), dentro del departamento de comunicación. Es decir, la comunicación de crisis es gestionada dentro de los departamentos de comunicación de las diversas administraciones públicas.

Los responsables de comunicación en las instituciones se deben esforzar por mantener una relación fluida y cercana con los medios de comunicación, mostrando interés por su conocimiento, por dispensarles un trato correcto y por facilitarles los recursos necesarios para el desarrollo de su trabajo (Canel, 2010). En una situación de crisis, donde los acontecimientos fluyen a un ritmo vertiginoso, el responsable del departamento de comunicación tiene una tarea muy importante en la gestión de la situación anómala. En una situaciones de crisis es cuando se precisa mayor destreza de las oficinas de comunicación (Dader, 2004). En el caso de las administraciones públicas estudiadas, la persona que asume la responsabilidad de la comunicación de crisis es el director de comunicación en un $66,7 \%$ de los casos (Gráfico 2). Este responsable suele ser personal de confianza $^{2}(75,6 \%)$ y en menor medida un funcionario de carrera $(15,6 \%)$ como se muestra en el Gráfico $3^{3}$.

GRÁFICO 2. RESPONSABLE DE LA COMUNICACIÓN DE CRISIS ¿Quién es el responsable de la comunicación en situaciones de crisis?

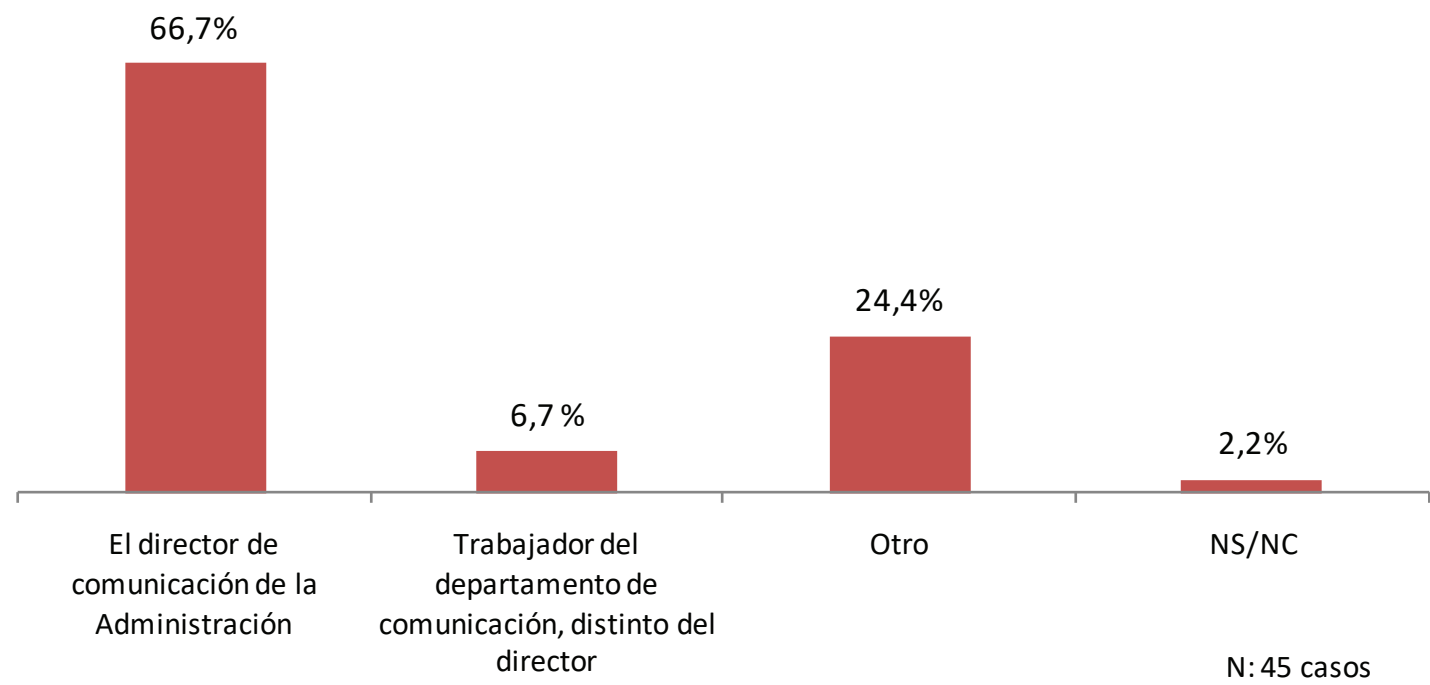

2 El personal de confianza es un tipo de empleado público que entra a formar parte de la Administración Pública en virtud de nombramiento por una autoridad pública. Son puestos de confianza y su duración suele ir unida al de la autoridad que lo nombró.

${ }^{3}$ En el Gráfico 3 nos referimos al personal que asume la dirección de comunicación. En las opciones de respuesta encontramos al funcionario de carrera, personal eventual y una tercera categoría «otro» diferente de las anteriores. En esta categoría se incluye cargo político y empresa que gestiona un contrato de servicios. 
GRÁFICO 3. RELACIÓN DE LOS RESPONSABLES DE LA COMUNICACIÓN DE CRISIS ¿Qué tipo de vinculación guarda el responsable de la comunicación de crisis con la organización?

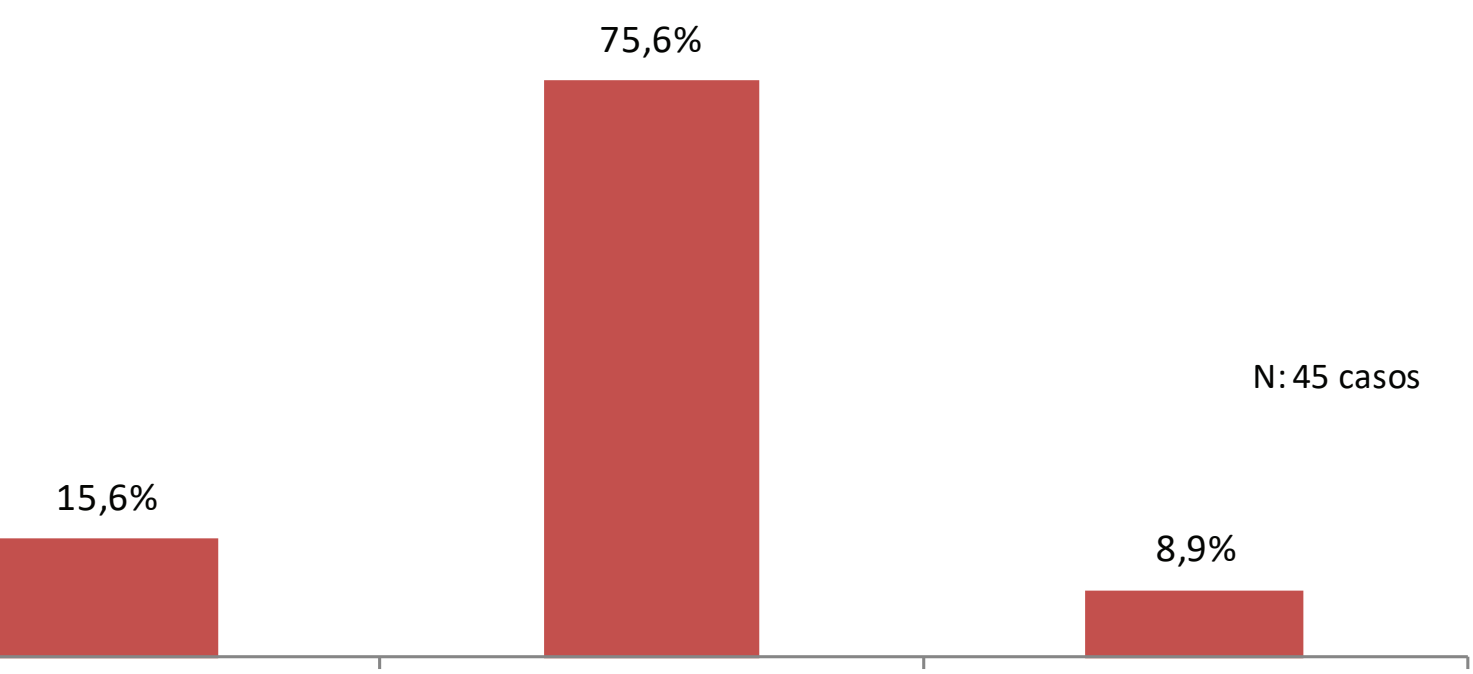

Funcionario de carrera

Personal de confianza

Otro

La asignación presupuestaria en materia de comunicación de crisis no viene recogida de forma expresa en la mayoría de las administraciones públicas. En la práctica totalidad de ellas se incluye dentro del presupuesto de «comunicación» de forma genérica, e incluso existen entidades sin presupuesto en esta materia.

\section{LA FASE DE PREVENCIÓN O PRE-CRISIS}

Las crisis se presentan de forma inesperada o precedida de señales de alerta que avisan de su llegada. La gestión de la crisis no se debe reducir a las medidas reactivas. Lo correcto es remontarnos a los momentos anteriores a su aparición. Es en la misma preparación y planificación de una crisis donde debe arrancar su gestión. «Mientras que para algunos la gestión de crisis tan solo consiste en una serie de medidas más o menos urgentes que se han de tomar ante la existencia de un problema, para otros la gestión de crisis comienza mucho antes e incluye medidas de previsión y planificación (existiendo, por tanto, gestión de crisis aun cuando nunca llegue a darse una situación de este tipo)» (González Herrero, 1998: 37).

Entre las medidas de prevención de una crisis, que evidencian la apuesta por una gestión proactiva, encontramos: la auditoría de crisis, la definición de los escenarios o posibles amenazas, los simulacros y la existencia de un manual de crisis. En estos manuales se definen las estrategias y tácticas que se deben poner en práctica ante la llegada de un fenómeno de estas características.

\subsection{Auditorías de crisis}

Aproximadamente, tres cuartas partes de las administraciones públicas estudiadas no realizan procesos de auditorías en materia de comunicación de crisis (Gráfico 4). En los casos en que éstas se desarrollan, en el $83,3 \%$ de ellos, la función de coordinación la realiza el mismo director de comunicación de la organización. En estas auditorías participan principalmente los responsables asignados a la gestión de la comunicación de crisis, además de funcionarios y responsables de otros departamentos, siendo menos frecuente la participación de personal ajeno a la organización. En el momento de efectuar la auditoría, ésta afecta al conjunto de la organización en la mitad de los casos, siendo menos frecuente para departamentos específicos. 
GRÁFICO 4. AUdiTORÍAS DE CRISIS EN LAS ADMINISTRACIONES PÚBLICAS ¿Se realizan auditorías de crisis en la organización?

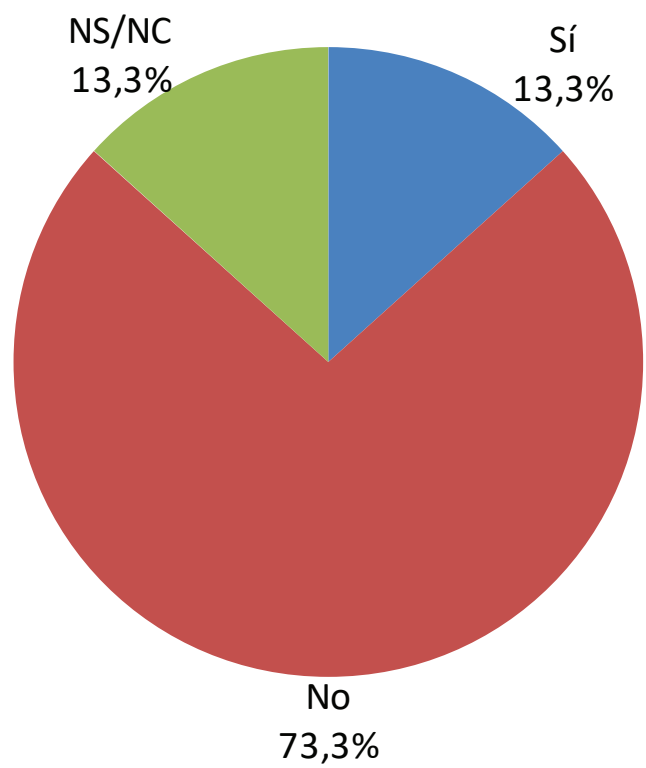

$\mathrm{N}: 45$ casos

\subsection{Identificación de amenazas para la organización}

Tal y como se observa en el Gráfico 5, a la hora de identificar posibles amenazas para la organización se tienen en cuenta a distintos grupos específicos: públicos clave, análisis 2.0 , una perspectiva histórica sobre hechos pasados en la organización y reuniones con responsables de departamentos, así como mapas de públicos y grupos de interés (stakeholders), clasificación de riesgos en áreas, análisis de otras crisis pasadas en el sector, informes de otras organizaciones y reuniones con funcionarios. En un segundo plano quedarían la consulta en foros especializados, la clasificación de riesgos en niveles, el estudio de revistas especializadas y la contratación de expertos y el uso de encuestas a la población.

GRÁFICO 5. DEFINICIÓN DE AMENAZAS PARA LA ADMINISTRACIÓN PÚBLICA.

¿QUÉ ELEMENTOS SE TIENEN EN CUENTA PARA DEFINIR POSIBLES AMENAZAS PARA LA ORGANIZACIÓN?

Elaboración de mapas de públicos y grupos de...

Consulta o asistencia a foros especializados

Clasificación de los riesgos en áreas

Clasificación de los riesgos en niveles

Análisis sectorial: Benchmarking

Análisis 2.0 (blogs, redes sociales)

Análisis histórico de las crisis pasadas de la...

Estudio histórico de casos de crisis en el sector

Estudio de revistas especializadas

Informes de otras organizaciones

Contratación de expertos

Reuniones con públicos clave

Reuniones con funcionarios

Reuniones con responsables de departamentos

Encuestas a la población

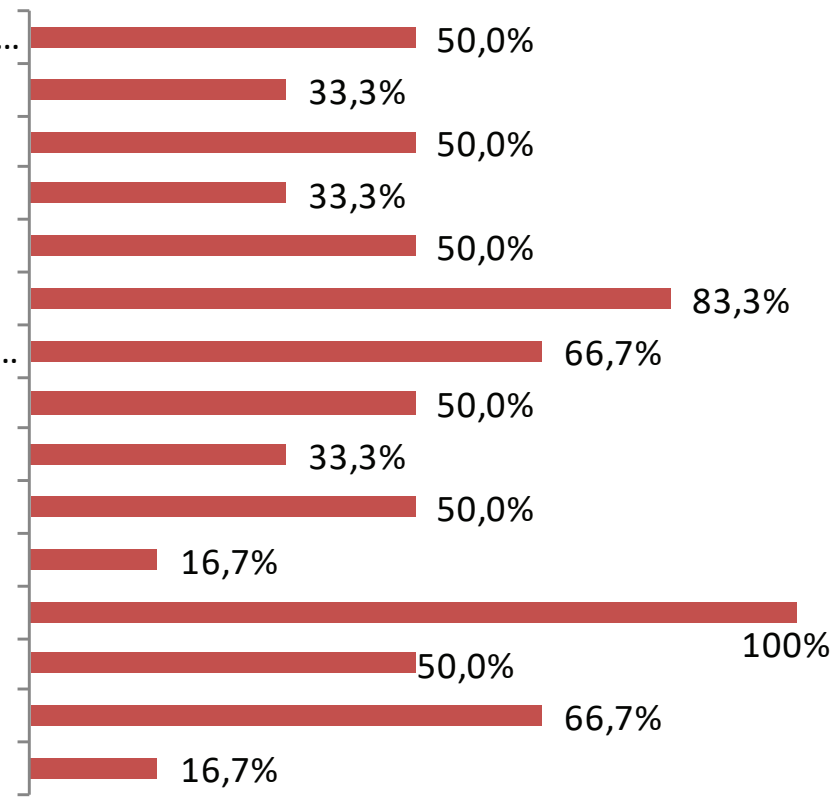


En los estudios de crisis concretas, se han alcanzado dos conclusiones sobre la identificación de las mismas. En primer lugar, los protagonistas suelen vacilar en cuanto a la conceptualización misma del término «crisis» (Riorda, 2016: 100-101). Así, el primer interrogante que se plantea, en muchos casos, es si, efectivamente, nos encontramos ante una verdadera situación de crisis o sólo ante un problema o un «incidente normal» (Brändström y Kuipers, 2003); sólo la simpleza de esta cuestión determina que se aborde la gestión de comunicación con sus variables más características y que se aplique un determinado protocolo de acción.

El asesor de Blair, Alistair Campbell, lo ha explicado muy gráficamente: «Durante un tiempo, coleccionaba titulares de crisis y aquí hay una selección de un mes: la crisis de A\&E, la crisis de la industria aérea, la crisis del control del tráfico aéreo, la crisis de las cenizas del volcán, la crisis del asilo. Esto sólo en la "A". Al final del alfabeto teníamos una crisis de profesores, una crisis turística, una crisis universitaria, una crisis de hostelería, una crisis penitenciaria y una crisis de músicos galeses.... Sin embargo: pocas si alguna de éstas eran crisis genuinas. Eran problemas... Las crisis son relativamente raras... Entonces, ¿qué es una crisis real? Bueno, yo podría escoger cinco (sí, sólo cinco) crisis completas, de 24 quilates, indudables, en las que estuve envuelto en Downing Street: el 11/S y la subsiguiente guerra en Afganistán, Irak en varios momentos, la intervención en Kosovo, las protestas de los carburantes en 2000 y la epidemia de fiebre aftosa en $2001 . .$. Esto me lleva al centro de lo que es una crisis: no es algo que ha ido simplemente mal-después de todo, hay cosas que van mal todo el tiempo y son fácilmente corregidas: es un acontecimiento o situación que amenaza con superarte si se toman las decisiones erróneas para tratarla... Si bien la crisis de la fiebre aftosa de 2001 y las protestas de los carburantes pueden no haber sido crisis a una escala global, eran crisis en sí mismas, no sólo porque en los primeros días en ambos casos el gobierno había perdido el control y no tenía respuestas... ¡Escasez de alimentos ¡iservicios públicos cerrados! ¡Recurrir a los militares para mantener el país en movimiento! Ahora estás realmente hablando de una crisis.» (Campbell, 2015: 319-321).

Los casos auditados ${ }^{4}$ facilitan una identificación rápida de algunos de los requisitos presentes en una situación crítica. Se aprecia en la desestabilización, el estrés y la reducción de los tiempos que condiciona la toma de decisiones, la emoción de los públicos afectados, la presión mediática, el desafío para la imagen de la organización administrativa o el peligro para la posición de poder de los decisores dentro de la organización. En todos los casos se produce el desequilibrio y la ruptura con el funcionamiento normal de las administraciones, mientras en la agenda pública y mediática hacen entrada, para quedarse, nuevos issues.

También se ha constatado que muchas crisis son difícilmente previsibles. Desde el punto de vista de la probabilidad de que suceda una crisis, por los indicios previos, los casos del Ébola y el plante de los controladores aéreos son ejemplos de típicas crisis inextricables o convencionales. En cambio, la imprevisibilidad de crisis como la de Lorca o la suscitada por los atentados terroristas del 11-S y del 11-M, donde no se puede predecir a priori el capricho de la naturaleza o la maldad de la acción terrorista, se corresponden más bien con crisis inesperadas o fundamentales. Las crisis convencionales (conventional crises) son crisis previsibles y sobre las que los líderes políticos o los directivos públicos pueden ejercer una cierta influencia, a diferencia de las crisis intratables (intractable crises), que son fácilmente previsibles pero muy difícilmente influenciables y gestionables. En cambio, de los dos tipos de crisis más difíciles de prever, las crisis inesperadas (unexpected crises) son más fácilmente influenciables y manejables que las crisis fundamentales (fundamental crises).

TABLA 2. TIPOS DE CRISIS SEGÚN SU PREVISIBLIDAD Y SU INFLUENCIABILIDAD

\begin{tabular}{l|l|l|l}
\hline \multicolumn{3}{c}{ Influenciable } \\
\hline \multirow{2}{*}{ Previsible } & \multirow{3}{*}{ Fácil } & $\begin{array}{l}\text { CRISIS CONVENCIONALES } \\
\text { Crisis de controladores aéreos. }\end{array}$ & $\begin{array}{l}\text { CRISIS INTRATABícil } \\
\text { Ébola. } \\
\text { Gripe A. }\end{array}$ \\
\cline { 2 - 5 } & \multirow{2}{*}{ Difícil } & $\begin{array}{l}\text { CRISIS INESPERADAS } \\
\text { Terremoto de Lorca. }\end{array}$ & $\begin{array}{l}\text { CRISIS FUNDAMENTALES } \\
\text { Atentados del 11-M/ 11-S. }\end{array}$ \\
& & & \\
\hline
\end{tabular}

Fuente: Adaptada de Gundel, 2005: 112

4 Los casos auditados son a los que nos hemos referido en el apartado del diseño de la investigación, estos son: El cierre del espacio aéreo (2010); el terremoto de Lorca (2011); el conflicto en Gamonal (2014); el contagio por el virus Ébola (2014). 
La proactividad, como situación ideal en la gestión de crisis, es un desideratum que no siempre se corresponde con la realidad. De hecho, en los casos que son objeto de análisis no siempre se observa una planificación y definición de escenarios acerca de lo que puede ocurrir y las medidas que se pueden poner en marcha para dar cauce a la resolución de los conflictos abiertos. La observación de los conflictos potenciales pudiera allanar el camino de las actuaciones, especialmente para detectar las señales de alerta que dispongan la entrada en acción de las medidas necesarias para reducir el conflicto, especialmente en las crisis convencionales.

En los casos que hemos estudiado, se apuesta de manera decidida por una actitud proactiva en un caso paradigmático de crisis convencional, la del cierre del espacio aéreo en el puente de diciembre del año 2010, puesto que desde que se encona la relación con el colectivo de controladores se articulan los medios para estar preparados y se contemplan las diferentes opciones de respuesta.

El caso de Gamonal es llamativo, puede ser una muestra de cómo no se interioriza la importancia de la comunicación en la situación de crisis más allá de planes o programas de emergencias climatológicas. Se tiene diseñado un plan de crisis con un comité y acciones para responder ante la descomprensión de la central nuclear y casos de climatología adversa, pero no ocurre igual para otros posibles conflictos potenciales.

Por su parte, el terremoto de Lorca, es un ejemplo obvio de crisis inesperada, no cuenta con un desarrollo de medidas proactivas, pero puede considerarse un caso de éxito, porque otras variables hacen fácilmente manejable e influenciable la crisis y producen efectos positivos sobre el resultado final (contexto, modelo de gestión y tipo de crisis).

Finalmente, en la crisis del Ébola, un caso de crisis intratable, los planes de emergencia se circunscriben más al ámbito sanitario y la comunicación se empieza a desarrollar cuando se decide la repatriación de los misioneros.

Un aspecto complementario que no hay que olvidar es la posibilidad de que crisis centrales o primarias desencadenen crisis laterales o secundarias, como es frecuente que suceda en ciudades que se han visto sacudidas por una catástrofe natural, como Lorca, o afectadas por ataques terroristas, como Nueva York, París, Londres o Madrid, e incluso países en situación casi de excepción por graves epidemias como la influenza en México o la fiebre aftosa en el Reino Unido. En todas ellas, se produjo una «extensión lógica de la crisis central» con el descenso del turismo, que provocó una crisis lateral para la que también hay que desarrollar una estrategia de comunicación (Campbell, 2015: 335-336).

\subsection{Simulacros de crisis}

Hemos analizado la previsión de la administración a través del desarrollo de auditorías, ahora estudiamos la gestión de simulacros. La importancia de las dos acciones, auditoría y simulacro de crisis, resulta positivo, pues un grupo sin un entrenamiento de crisis se encuentra más limitado cuando se enfrenta a una situación real (Lagadec, 1997:5).

Casi ocho de cada diez de las administraciones públicas entrevistadas que afrontan la comunicación en situaciones de crisis no llevan a cabo simulacros de crisis. Tan sólo cinco entidades $(11,1 \%)$ de las analizadas tomaron este tipo de medidas de preparación ante posibles situaciones de crisis.

El posterior seguimiento de estos cinco casos evidencia determinadas pautas como la importancia de la figura del director de comunicación de la organización (en el $40 \%$ de los casos, siendo en el $20 \%$ un trabajador del departamento de comunicación, diferente del Dircom), la periodicidad anual o bianual de estos simulacros o la inclusión de la totalidad de la organización en este proceso (en el $60 \%$ de los casos analizados $)^{5}$.

Estos simulacros raramente toman en cuenta la duración y los posibles perfiles y trayectorias de las crisis. Sin embargo, estos aspectos han resultado muy relevantes para la planificación de la comunicación en los casos estudiados. En este sentido, por lo que respecta a la duración de la crisis, una vez que se desencadena la fase de eclosión, el tiempo que resta hasta alcanzar el cierre es muy significativo. Entre nuestros casos de estudio, la de mayor duración es la del Ébola, no ya por su gestión en sí misma sino por la necesidad de sobrepasar el periodo de tiempo establecido en los protocolos sanitarios internacionales para descartar el desarrollo de la enfermedad. La crisis que menos tiempo ocupa en la portada

5 Los casos a los que se hizo un seguimiento especial para la investigación presentada al INAP dado que sí realizaban de manera periódica simulacros fueron: Ayuntamiento del Prat de Llobregat, Ayuntamiento de Cartagena, Comunidad de Castilla-La Mancha, Ministerio de Sanidad y Ayuntamiento de San Bartolomé de Tinajara (Gran Canaria). 
de los medios y en los titulares de los informativos es la del cierre del espacio aéreo: apenas tres días, que es el tiempo necesario para la recuperación de la normalidad aeroportuaria. La actuación previsora, en este caso, abrevió su duración y las medidas que introdujo el gobierno mediante el Real Decreto ${ }^{6}$ de 3 de diciembre de 2010 permitieron disponer de los instrumentos para reabrir los aeropuertos en un plazo breve.

En el análisis de los casos de estudio hemos encontrado, asimismo, diferentes ejemplos de las dos trayectorias de crisis más frecuentes con las que se encuentran los responsables públicos: las crisis de combustión rápida y las crisis de larga sombra (Boin, Hart, Stern y Sundelius, 2007: 117-122). Las primeras, las crisis de combustión rápida (Fast burning crisis), son intensas y breves, consecuencia de calamidades y desastres naturales como seísmos, huracanes, maremotos, etc. (Fox-Gotham y Greenberg, 2014; Vale y Campanella, 2005). El ejemplo del terremoto de Lorca es el caso paradigmático de una crisis de combustión rápida, aunque otro de nuestros casos de estudio, el relativo al plante de los controladores aéreos, es una buena ilustración de crisis con este mismo tipo de trayectoria. Otros casos similares son los derivados de secuestros aéreos o tomas de rehenes que requieren la intervención de operativos militares, o crisis como la de la fiebre aftosa en el Reino Unido en 2001 o la ola de calor en Francia en 2003 (Drennan y McConnell, 2007: 18). Estas crisis se caracterizan, además, por la simultaneidad del cierre operativo y el cierre político de las mismas. El cierre rápido, tanto político como operacional, de esas crisis se ve facilitado por la concurrencia de tres condiciones: en primer término, el carácter ordinario de la misma, esto es, que el fenómeno a afrontar no sobrecargue las capacidades de los servicios de respuesta, lo que resulta más probable en comunidades sometidas con cierta frecuencia a estas eventualidades (terremotos en Japón, huracanes en el Caribe, Mississippi o Nueva Orleans, tornados en Florida, etc.); en segundo lugar, la ausencia de foros ciudadanos o asociaciones de víctimas que exijan procesos de rendición de cuentas y de exigencia de responsabilidades; $y$, en tercer lugar, la aparición de una emergencia o crisis posterior de mayor dimensión aún, que eclipse a la primera.

Las crisis de sombra alargada (Long shadow crisis), en cambio, se definen por separar el cierre operativo y el cierre político de las mismas y por prolongarse en las arenas políticas y sociales después de que las amenazas o la situación de crisis se haya desvanecido. En España, los ejemplos del Prestige, de los atentados terroristas del 11-M o del accidente del metro en Valencia ilustran bien este tipo de trayectoria, al igual que crisis como la de la tragedia del estadio de Heysel en 1985, los disturbios raciales de Los Ángeles a principios de los años noventa, la crisis de las tropas holandesas en la masacre de Srbrenica o los casos de Stephen Lawrencen en 1993 y el affaire de David Kelly y la BBC en el Reino Unido (Drennan y McConnell, 2007: 19). Estas crisis de sombra alargada llegan a ser vistas como indicadores de problemas más profundos y pueden sacar a la luz fallos en los arreglos existentes de prevención y de preparación, que provocan el escrutinio intenso de las estructuras institucionales.

En algunos casos, las crisis escalan hasta convertirse en verdaderas crisis institucionales plenamente desarrolladas, en «retos fundamentales para las estructuras organizativas o los paradigmas de política pública.» (Boin, Hart, Stern y Sundelius, 2007: 120). Esta trayectoria es la habitual en crisis «incomprensibles» (debidas a situaciones o incidentes que causan una profunda conmoción y son, a su vez, desconcertantes por suceder en lugares donde la planificación o la previsión nunca las contemplarían), «mal gestionadas» (a causa de respuestas lentas, ineficientes o inadecuadas que transforman simples incidentes policiales o delictivos en graves crisis raciales, como los sucesos de Los Ángeles en 1991 o de Ferguson, Missouri, en 2014) o de agenda-setting, de establecimiento de temas en la agenda política (proporcionan una policy window o ventana de oportunidad, por usar el ya clásico término de Kingdon, para que ciertos incidentes se conviertan en un tema de la agenda política, como ha sido frecuente, por ejemplo, con los accidentes de plantas nucleares, que han servido de detonante para repolitizar el uso de la energía nuclear en diversos países). En nuestro país, el accidente del metro de Valencia en 2006 es un buen ejemplo de este segundo subtipo de crisis de larga sombra «mal gestionadas», puesto que «los incidentes mal gestionados también están relacionados con los muchos casos en que los grupos de víctimas sienten que no han sido atendidos

\footnotetext{
6 Real Decreto-Ley 13/2010, de 3 de diciembre, de actuaciones en el ámbito fiscal, laboral y liberalizadoras para fomentar la inversión y crear empleo. En el apartado $\mathrm{V}$ de su exposición de motivos se argumentan las principales reformas en la gestión de los aeropuertos, y se introduce la necesidad de convertir la entidad pública empresarial en sociedad estatal. Se incorporan dos modificaciones para garantizar el tráfico aéreo «sobre atención en caso de enfermedad y garantía del servicio bajo la dirección, si fuera necesario, del Ministerio de Defensa». Esta última garantía permitió que los controladores estuvieran bajo órdenes militares durante la declaración del estado de alarma, la reapertura de los aeropuertos y el cierre de la crisis en 72 horas.
} 
suficientemente y emprenden acciones políticas y legales contra las autoridades». Esto da lugar a luchas legales prolongadas y publicidad negativa, que puede durar fácilmente una década o más (Boin, Hart, Stern y Sundelius, 2007: 121).

Tipos de crisis menos frecuentes son las denominadas crisis catárticas y las crisis de combustión lenta (Boin y t'Hart: 2001: 32). Las crisis catárticas se caracterizan «por una terminación relativamente abrupta que sigue a una aparición lenta y gradual. Las tensiones o la vulnerabilidad van creciendo lentamente hasta que llegan a un punto crítico en el que algo se quiebra o las partes deciden forzar una ruptura. Esta pauta puede verse en muchos casos de conflicto entre las autoridades y grupos extremistas políticos o religiosos» (Olmeda, 2010: 1064), aunque los ejemplos clásicos de crisis con esta trayectoria son las derivadas de la persecución de asesinos seriales como el asesino de la baraja en España, Unabomber en Estados Unidos o el destripador de Yorkshire en el Reino Unido. Por su parte, las crisis de combustión lenta hacen referencia a «amenazas a largo plazo que se desarrollan lentamente pero que, raramente, alcanzan un punto crítico y permanecen típicamente sin resolver», como los problemas relativos al envejecimiento o a la obesidad, al calentamiento global, etc. (Drennan y McConnell, 2007: 19).

TABLA 3. TIPOS Y CASOS DE TRAYECTORIAS DE CRISIS

\begin{tabular}{|c|c|c|c|}
\hline \multicolumn{4}{|c|}{ Velocidad de desarrollo } \\
\hline & & Rápida: instantánea & Lenta: sigilosa \\
\hline \multirow{2}{*}{$\begin{array}{l}\text { Velocidad } \\
\text { de terminación }\end{array}$} & Rápida: abrupta & $\begin{array}{l}\text { Crisis de combustión rápida } \\
\text { Lorca. } \\
\text { Controladores aéreos. }\end{array}$ & $\begin{array}{l}\text { Crisis catártica } \\
\text { Asesino de la baraja y otras crisis } \\
\text { de asesinos seriales. }\end{array}$ \\
\hline & Lenta: gradual & $\begin{array}{l}\text { Crisis de sombra alargada } \\
\text { Prestige. } \\
\text { Atentado terrorista 11-M. } \\
\text { Metro de Valencia. }\end{array}$ & $\begin{array}{l}\text { Crisis de combustión lenta } \\
\text { Calentamiento global. } \\
\text { Envejecimiento. }\end{array}$ \\
\hline
\end{tabular}

Fuente: Adaptada de Boin y t'Hart, 2001: 32

Lo mismo cabe señalar respecto a la falta de previsión con relación a los posibles perfiles de la crisis y su tratamiento comunicativo. Los modelos dinámicos de comunicación de crisis no sólo plantean, como se ha indicado, un checklist distinto para cada momento de la evolución de toda crisis, sino que muestran que resulta conveniente considerar que la crisis describirá el típico «arco» temporal, que señala -entre otrosCampbell (2015), y lo más probable es que se produzca una mejora paulatina, más rápida o más lenta, en función del tipo de crisis. De este modo, el perfil de las crisis puede variar, como muestra el Gráfico 6, según las crisis exhiban una pauta más escalonada, más cíclica o más efímera o rápida y pasajera (González Herrero, 1998).

GRÁFICO 6. PERFILES DE SITUACIONES DE CRISIS

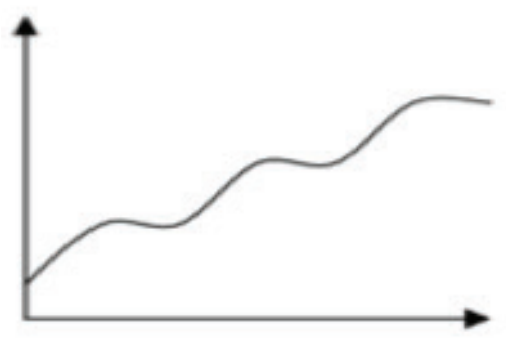

Escalonada

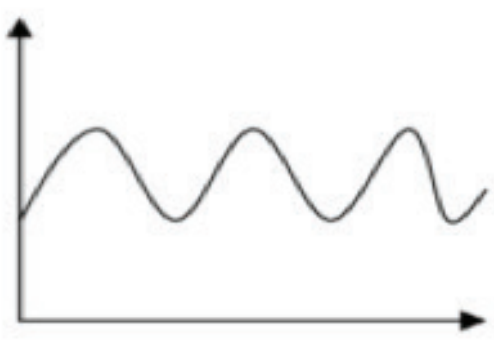

Cíclica

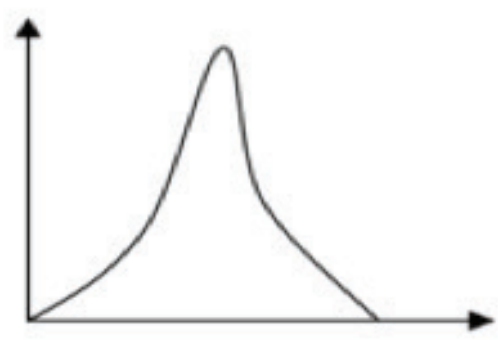

Pasajera

Fuente: González Herrero, 1998 
En este sentido, es aconsejable realizar un análisis exhaustivo de la comunicación de las administraciones públicas a través de las redes sociales en los casos de crisis para poder establecer el perfil que éstas adoptarán. Un buen ejemplo es la emisión de mensajes desde el perfil creado para la comunicación digital del caso del Ébola, que no sólo permite visualizar la dinámica informativa en las fases de eclosión, perversión y síntesis de la crisis sino que anticipa que estas crisis sanitarias podrían adoptar un clásico perfil de crisis de tipo cíclico, como muestra el Gráfico 7, correspondiente a las informaciones publicadas desde la cuenta institucional @sanidadgob.

GRÁFICO 7. PUBLICACIONES DE LA CUENTA DE TWITTER DEL MINISTERIO DE SANIDAD EN LA CRISIS DEL ÉBOLA Número de publicaciones diarias

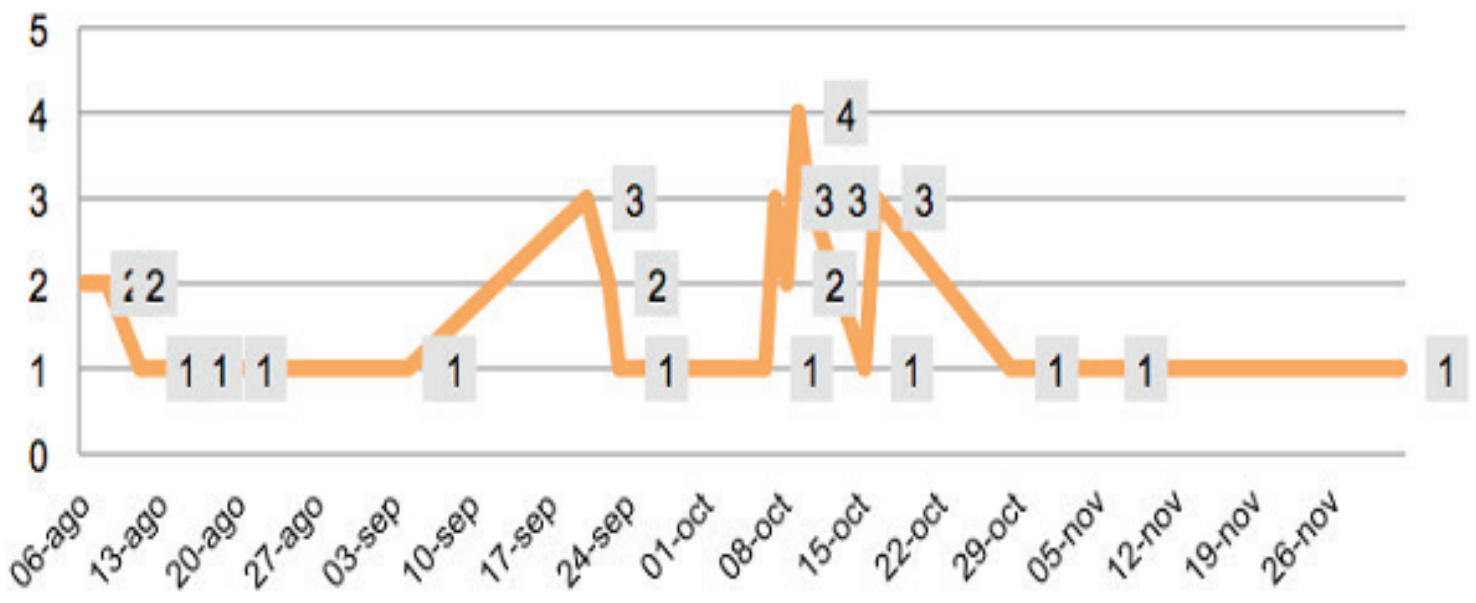

Fuente: Elaboración propia a partir de @sanidadgob

Obsérvese cómo la pauta informativa que esta crisis siguió en los medios de comunicación se aproximó a esta misma pauta, como muestra el Gráfico 8 , con el objeto de poder establecer un protocolo de actuación más calculado y racional para estos casos en el futuro.

\section{GRÁFICO 8. IMPACTO MEDIÁTICO POR TITULARES DE LAS NOTICIAS PUBLICADAS SOBRE LA CRISIS DEL ÉBOLA}
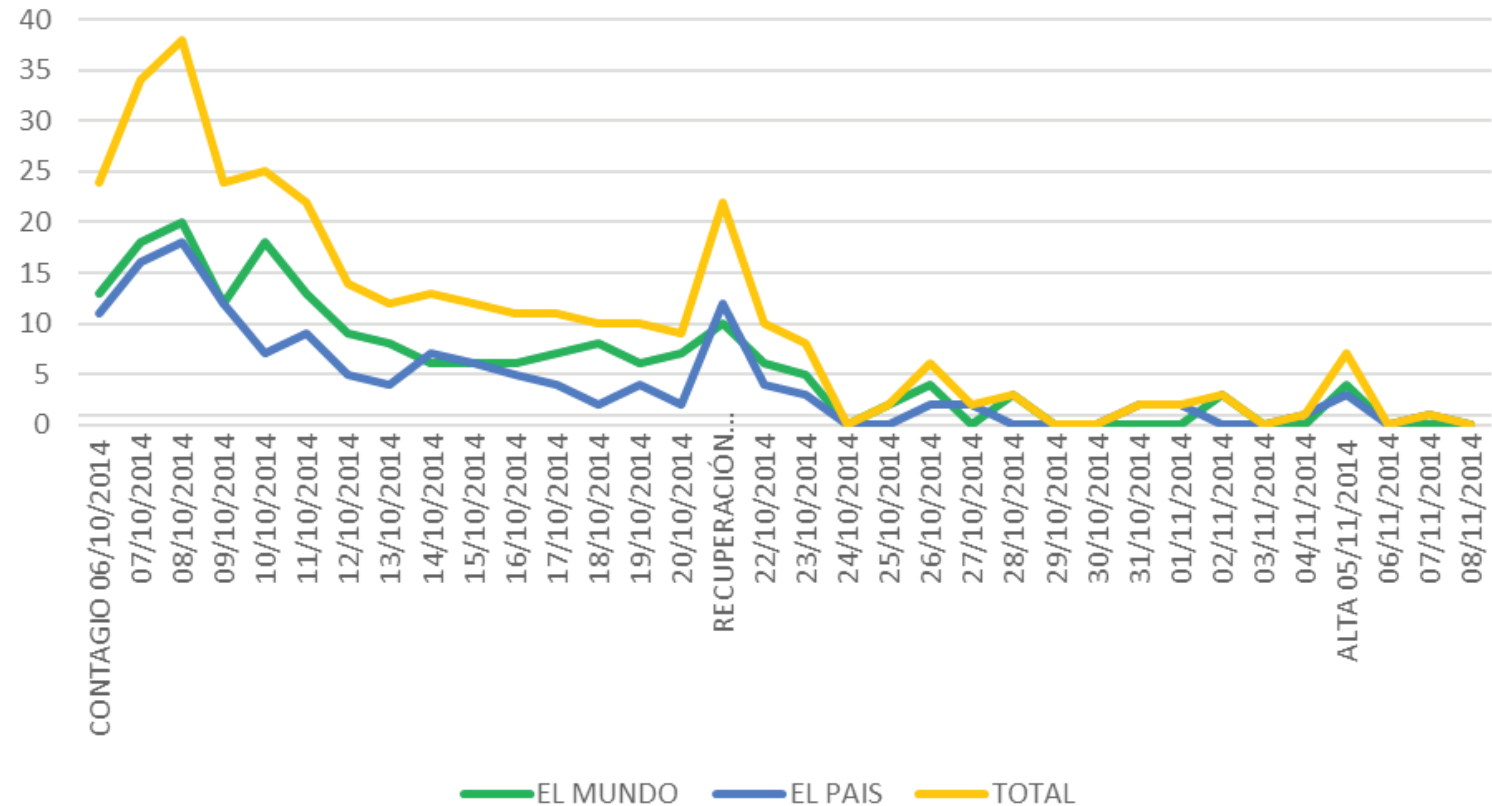

Fuente: Elaboración propia a partir de noticias publicadas por El Mundo y El País 


\subsection{Manual de crisis}

La planificación de una gestión de crisis tiene su máximo exponente en la redacción de un manual de crisis, preferiblemente ambicioso, donde se contemplen los posibles escenarios de crisis que condiciona la estrategia de gestión y comunicación. Las ventajas que aporta la planificación previa es que «puede trabajarse en su preparación sin la presión de los hechos consumados; evita el caos inicial inherente a toda crisis y garantiza en los primeros momentos una acción más rápida en lo fundamental, ante el agobio de los miles de detalles que es preciso solucionar sobre la marcha» (Paniagua, 2010: 8).

La importancia que tienen los manuales no es percibida de la misma manera por el sector público que por el sector privado; muestra de ello es la escasez de manuales de comunicación de crisis en las administraciones públicas. Esto es algo que queda demostrado para los casos auditados, a pesar de que en el caso del cierre del espacio aéreo se haya previsto una estrategia a raíz de detectarse lo que podía ser un escenario problemático.

La Administración Pública no dispone, por lo general, de mecanismos de prevención para casos de crisis y existe un amplio desconocimiento de ellos en algunas administraciones. Esta evidencia, patente en las auditorías de casos, se corresponde también con las encuestas realizadas y con las entrevistas a los directivos de comunicación que trabajan en la función pública, con la parcial excepción de la Administración General del Estado. Hay, en consecuencia, una escasa sensibilidad por la formación y prevención, pese a que la crisis se debe percibir, metafóricamente, como una enfermedad o epidemia ante la que nos debemos vacunar para que en el caso de desarrollar la enfermedad no dañe en exceso nuestro organismo ni tenga un reflejo negativo sobre nuestra salud.

Solamente tres de cada diez administraciones estudiadas (el $31,1 \%$ de los casos) que afrontan la comunicación en situaciones de crisis cuentan con un manual de crisis ${ }^{7}$. En aquellos casos en los que existe un manual sobre esta materia, se trata de un manual genérico o de una fórmula combinada en la que todos los sectores de la organización quedan incluidos, como muestra el Gráfico 9.

GRÁFICO 9. CARÁCTER DE LOS MANUALES DE CRISIS DE LAS ADMINISTRACIONES PÚblicAS ¿Se trata de un manual genérico para la orgnización o se realizan distintos manuales por sectores? $57,1 \%$

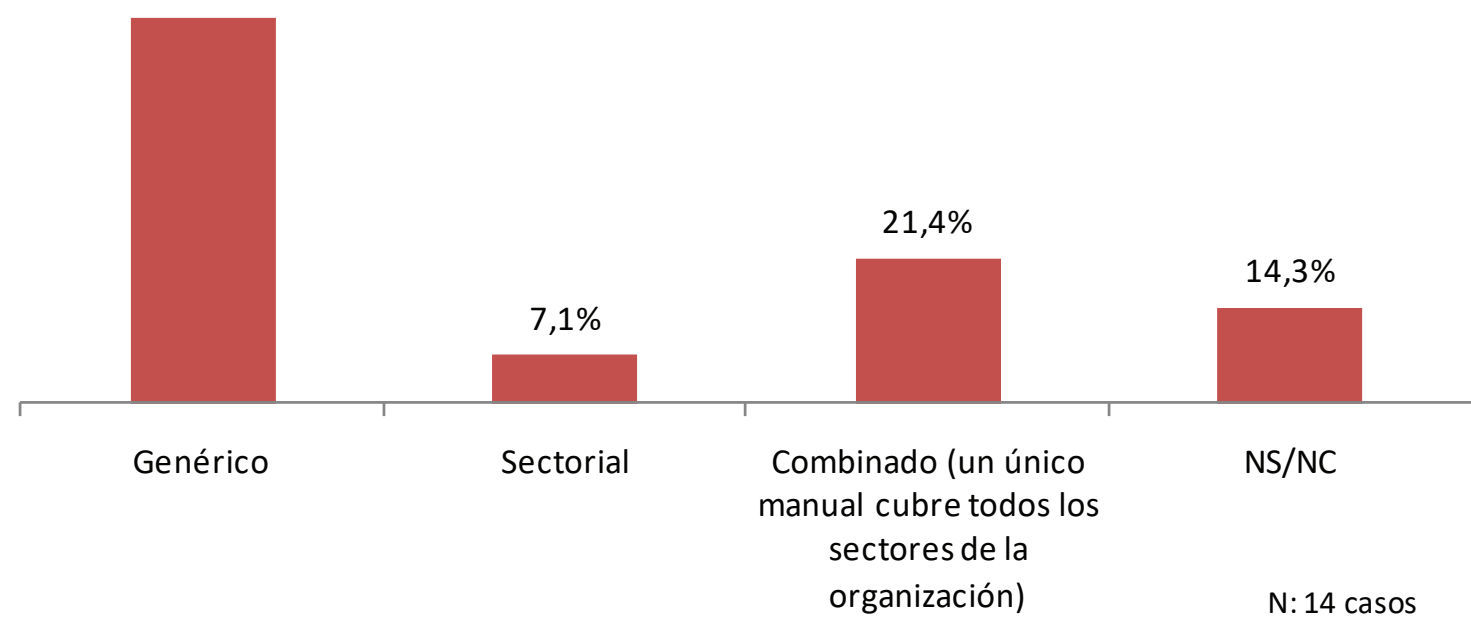

La periodicidad por la cual se actualiza el manual de crisis oscila entre los seis meses y más de dos años, siendo lo más frecuente un plazo superior a los dos años (Gráfico 10). Combinados los dos datos, la presencia en sólo un tercio de las administraciones públicas estudiadas de manuales de gestión y comunicación de crisis y el hecho de que en este pequeño grupo este manual no se actualice o se revise de manera episódica (en el $43 \%$ de los casos, un porcentaje que puede ser aún mayor, ya que el $21 \%$ de los encuestados no respondieron a esta pregunta), es una evidencia muy reveladora de la escasa importancia que las administraciones públicas otorgan a la gestión y la comunicación de las crisis.

\footnotetext{
7 Las administraciones públicas estudiadas en profundidad para la investigación presentada al INAP que contaban con un manual de crisis han sido: Ayuntamientos del Prat de Llobregat, Gandía, Santa Lucía, Mataró, Jerez de la Frontera, San Bartolomé de Tinajara (Gran Canaria), Granada, Alovera y Rubí, así como las Comunidades Autónomas de Castilla-La Mancha, Islas Baleares, Madrid, Navarra y Cataluña.
} 


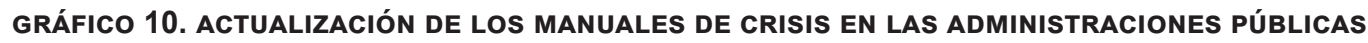
¿Cada cuánto se actualiza el manual de crisis?

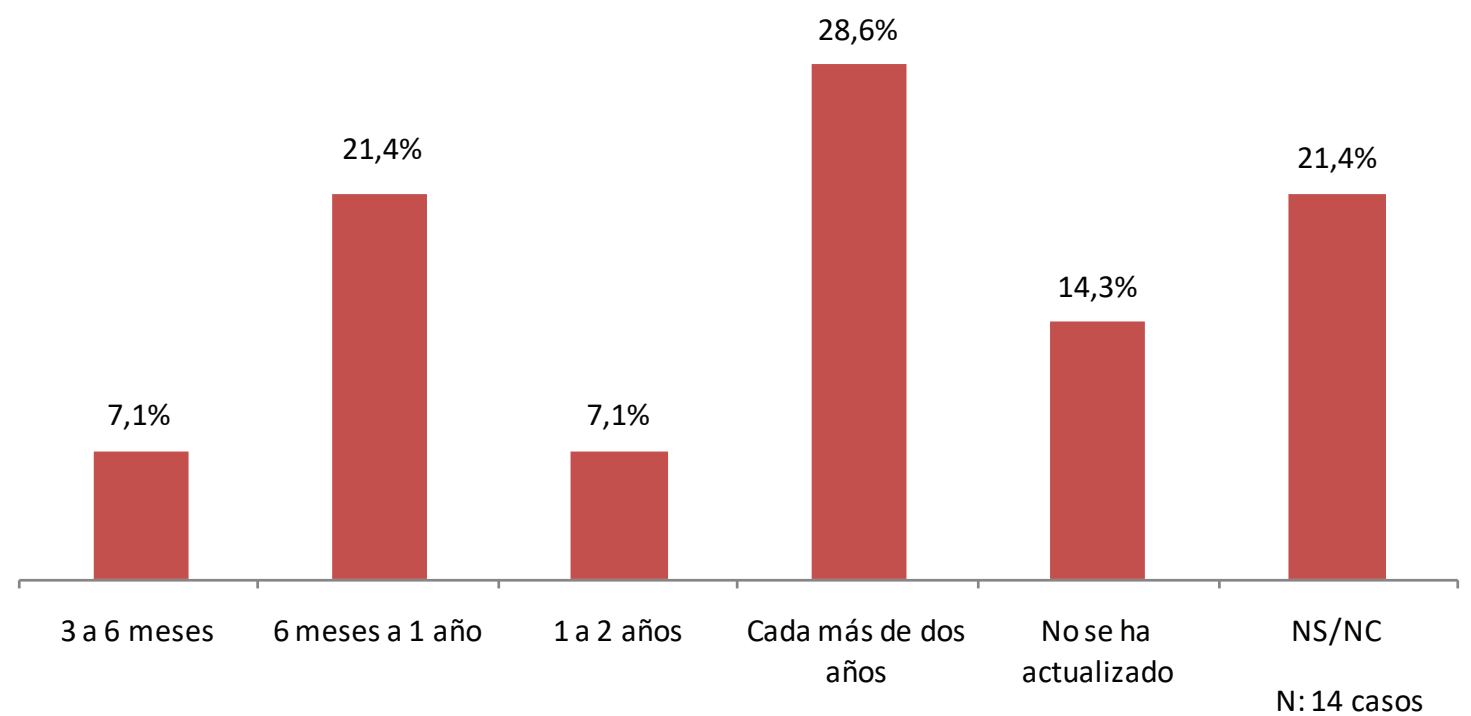

En estos manuales es frecuente encontrar elementos como una definición clara del papel del Comité de Crisis y del Portavoz, una especificación de canales de difusión del mensaje, estrategias generales ante crisis potenciales, configuración del comité de crisis, políticas de mensajes ante crisis potenciales, estrategias de relación con la prensa, una relación exhaustiva de posibles crisis y/o amenazas, sistemas de alerta, bases de datos con contactos específicos o medidas para la evaluación de crisis. Otros elementos que se encuentran, pero con menor frecuencia que los anteriores, son documentos predefinidos como respuesta a potenciales crisis, estrategias para la cultura de crisis o la creación de una web de crisis (Gráfico 11).

\section{GRÁFICO 11. ELEMENTOS INCLUIDOS EN LOS MANUALES DE CRISIS DE LAS ADMINISTRACIONES PÚBLICAS}

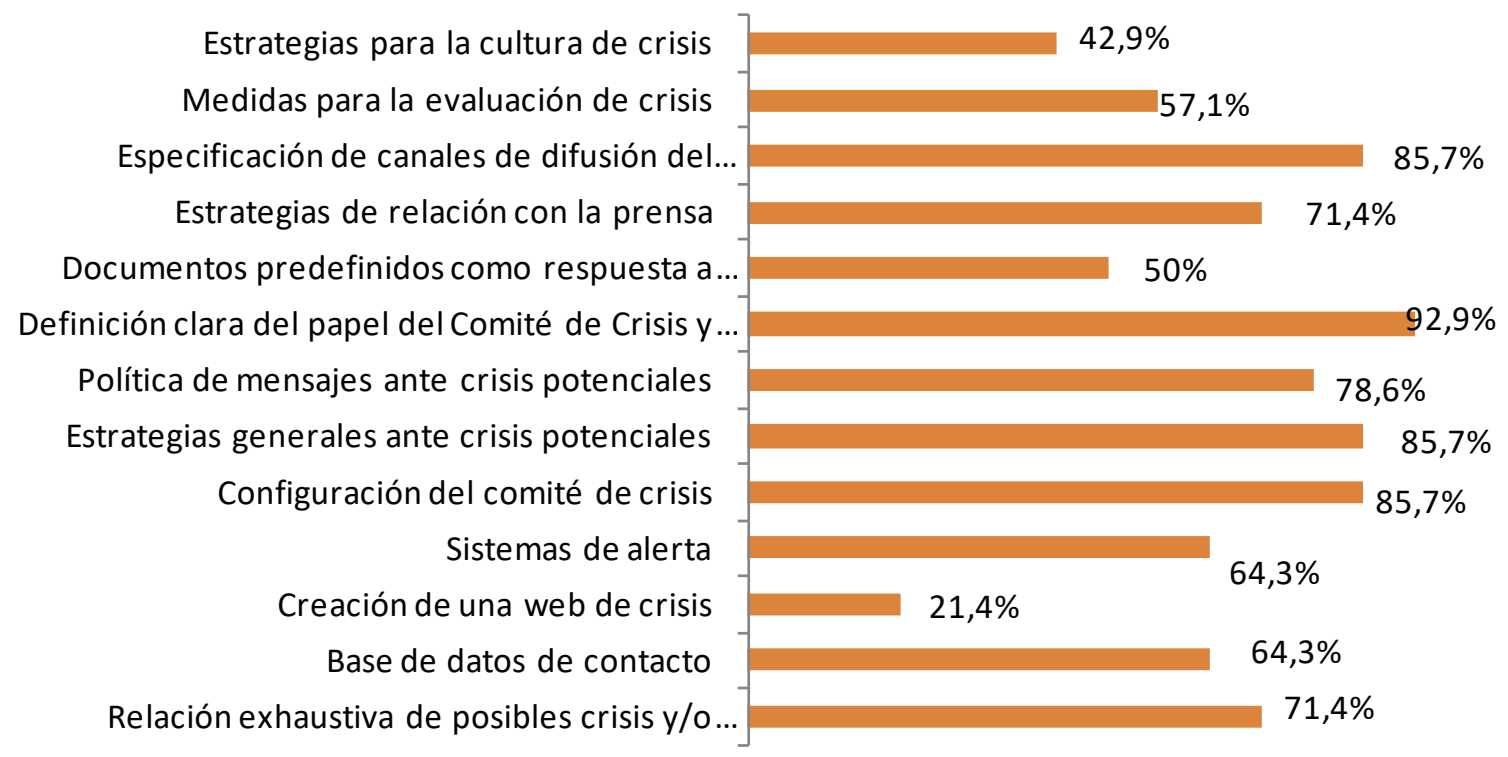

La práctica de los casos analizados nos acerca tanto a casos de comunicación de crisis que aplican un plan de comunicación, perfectamente diseñado y previsto, como, más frecuentemente, a casos con una estrategia de comunicación que se construye con la primera señal de alarma (en la fase de pre crisis) o incluso en el momento en que explota la crisis.

Desde luego, no siempre podemos afirmar que una estrategia de comunicación improvisada ha desembocado en una nefasta gestión del conflicto, si bien la gestión de la comunicación resulta más fácil si la 
estrategia responde a una planificación previa. «Muchas veces organizaciones que poseen un plan de crisis, no siempre la gestionan bien y, por el contrario, hay algunas que no tienen un plan de crisis y sin embargo han resuelto airosas la situación» (Cruz Sandoval, 2004: 211).

En algunos casos la estrategia resulta adecuada, pero en otros casos han jugado un papel relevante otras variables. La gestión de comunicación del terremoto de Lorca no contó con una planificación previa, ni disponía el consistorio de un manual de comunicación donde se indicaran las pautas a seguir. Sin embargo, se demostró una capacidad de respuesta que dio lugar a una estrategia de comunicación que cumple con los que consideramos axiomas de una eficaz comunicación de crisis en el marco de una Administración Pública: estrategia de decir la verdad, huir del silencio, trasladar la máxima información posible, cercanía con los medios de comunicación, transparencia, mensajes unívocos, portavoz único -que coincide con el máximo responsable-, empatía del líder, colaboración y cooperación entre administraciones, etc. Sin duda, hay tres variables que pudieron intervenir en este resultado en el caso lorquino: el modelo de gestión de crisis inevitable, el tipo de crisis (catástrofe natural sin responsable directo de la tragedia) y el contexto (campaña de las elecciones municipales y autonómicas), este último modeló el discurso único de las tres administraciones.

Otros casos respondieron a un modelo de gestión de crisis evitable con la presencia de señales de prealerta que anticipan la posible llegada de una crisis, pero no se reaccionó de la misma manera ante la presencia de esas señales de alerta: en el caso del cierre del espacio aéreo español la previsión comienza incluso antes del plante en el aeropuerto de Santiago ${ }^{8}$; en el caso de Gamonal, la estrategia es reactiva una vez que se produce la manifestación y se detienen las obras; en el caso del Ébola se empieza a trabajar en la comunicación cuando se decide repatriar a los dos misioneros; finalmente, en el caso de la crisis aérea, cuenta con un plan de crisis organizado al mínimo detalle de actuación, que se había preparado desde hacía tiempo, en una estrategia no solo de comunicación sino política que permite tener todo organizado cuando el conflicto se produce.

\section{LA FASE DE CRISIS}

\subsection{El Comité de crisis}

El comité de crisis es el «órgano, distinto de la dirección general, que permite aislar el tratamiento de la crisis de las otras funciones de la empresa, (...) asume una función de competencia reservada, sobre la base de la centralización (él y solo él, gestiona la crisis) y también de la exclusividad (el comité no ejerce ninguna otra función)» (Piñuel, 1997: 184). Dentro de este marco conceptual, lo ideal es que este órgano se encuentre aislado del resto del staff de toma de decisiones para un mejor desarrollo de sus competencias (Westphalen y Piñuel, 1993).

Las organizaciones que confían en una gestión de crisis proactiva no visualizan su comité de crisis como el órgano que entra en funcionamiento con la erupción de una crisis, sus miembros precisan de una formación adecuada y puede participar en las actividades de preparación de la misma. En este sentido, resulta habitual encontrar comités de crisis que se reúnen para afrontar situaciones peliagudas o delicadas (González Herrero, 1998: 167), aun cuando no se haya pulsado el botón de alarma de la crisis. De manera contraria, cuando se realiza una creación ad hoc de un comité de crisis, generalmente se puede dar por dos mecanismos: por pedido del organismo que se ve directamente afectado por la crisis o por decisión política, dado los acontecimientos producidos.

Más de la mitad de las entidades encuestadas $(51,1 \%)$ no posee en su estructura orgánica un Comité de crisis. En aquellas organizaciones dónde existe este Comité (aproximadamente en el $44,4 \%$ de las administraciones), dicho Comité está configurado por puestos de responsabilidad, entre ellos directores de comunicación y otros altos cargos de la Administración Pública. No obstante, la mayoría de éstos se muestran abiertos a la implicación de expertos en tipos de crisis específicos (Gráfico 12) con protocolos preestablecidos de contacto rápido entre los integrantes de los comités, aunque no se diseña como una figura con existencia permanente dentro de la organización (sólo es permanente en el $55 \%$ de los casos). En los casos analizamos, los comités de crisis disfrutan de una autonomía moderada en la toma de decisiones (de 5 a 8 puntos en una escala de 0 a 10 ) .

\footnotetext{
8 El cierre del espacio aéreo el 3 de diciembre de 2010, fue precedido por los hechos ocurridos en el aeropuerto de Santiago de Compostela. Se producen cancelaciones de vuelos ante la ausencia de controladores en las torres de control. Estos hechos permiten al Gobierno anticiparse y recoger en una norma legal las medidas necesarias para reducir las situaciones de abandono de los controladores de sus puestos de trabajo.

9 Los comités de crisis estudiados en mayor profundidad para la investigación realizada para el INAP pertenecen a los Ayuntamientos de Alovera, Torrent, Granada, San Bartolomé de Tinajara (Gran Canaria), Cartagena, Telde, Avilés, El Prat de Llobregat, Gan-
} 
GRÁFICO 12. TIPOS DE COMITÉS DE CRISIS EN LAS ADMINISTRACIONES PÚBLICAS ¿Se trata de un comité genérico o está asociado a la tipología de la crisis?

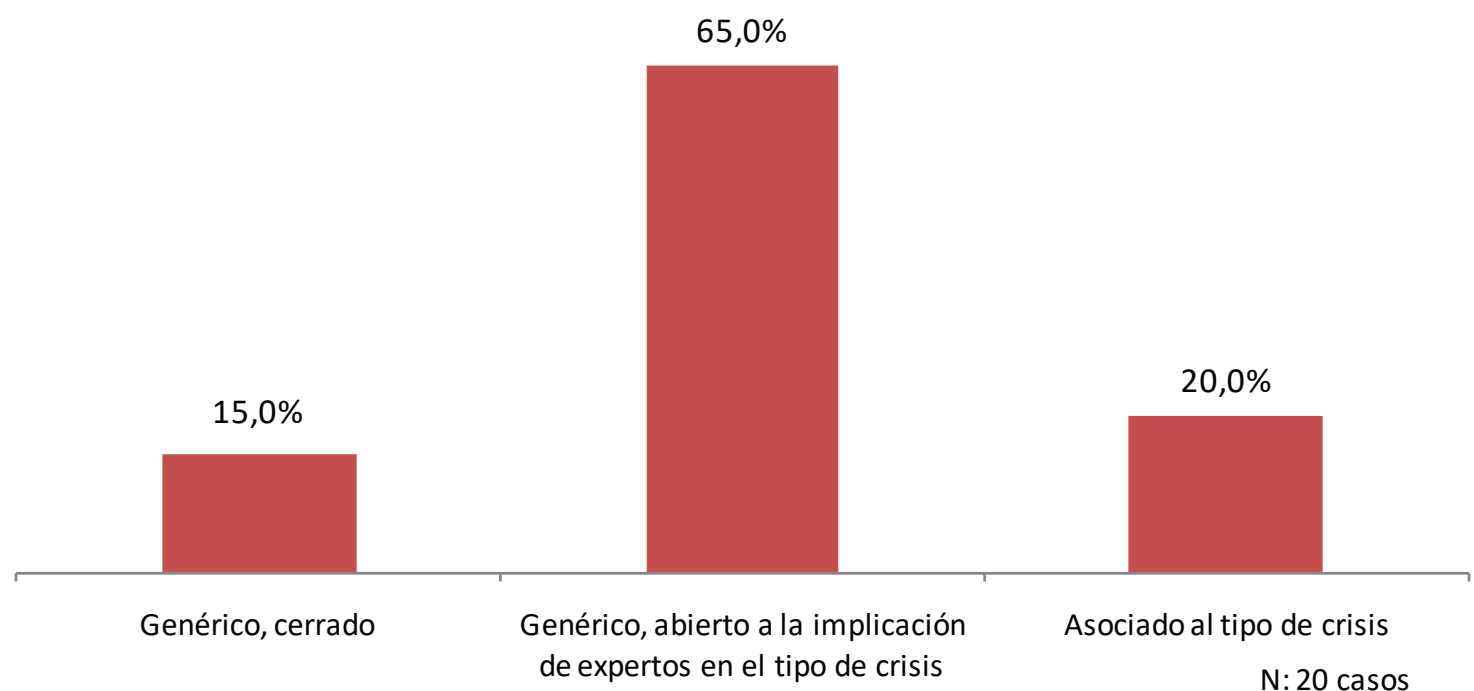

\subsection{La figura del portavoz}

La designación del portavoz no puede quedar a merced de la improvisación; su selección y formación no es una decisión baladí. La actuación del portavoz puede condicionar la percepción en los públicos en la gestión de la comunicación de una crisis.

En las administraciones públicas españolas que afrontan la comunicación en situaciones de crisis, esta función recae sobre distintas figuras, dependiendo del tipo de administración de que se trate, destacando la figura del representante o líder político de la institución, siendo menos frecuente un perfil profesional con formación específica en este ámbito. También es poco frecuente, aunque sí existe en algunas administraciones, una figura diferenciada para distintos tipos de crisis. Siete de cada diez organismos públicos que cuentan con una figura de portavoz (el $71,4 \%$ ), realizan procedimientos de entrenamiento en sus facetas comunicacionales (media training o relaciones con los medios de comunicación), mientras que un $21,4 \%$ no lleva a cabo ninguna estrategia de entrenamiento.

La importancia en estas crisis de la figura del portavoz aparece en el análisis detenido de los casos ${ }^{10}$. En este ámbito, existen básicamente dos cuestiones a resolver: el número de portavoces de la crisis, y la presencia o no de voces de expertos según la tipología del conflicto.

Lo más adecuado es que haya un portavoz único, para evitar las contradicciones en las comparecencias públicas y la confusión de los ciudadanos, de los públicos y de los medios de comunicación, que no saben con nitidez a quién deben dirigirse para conocer los datos de la tramitación de la crisis. Cuando no se puede abordar la crisis con una voz única, los canales de comunicación interna que se tengan previstos deben favorecer la coordinación entre los portavoces (Freijeiro, 2010: 319). Para evitar esa posible duplicidad de mensajes y de órganos decisores, lo aconsejable es que el portavoz sea el coordinador y el director del comité de crisis.

En el terremoto de Lorca, el portavoz fue el propio alcalde quien acaparó el protagonismo de todas las medidas puestas en marcha, mientras el resto de administraciones públicas implicadas en la gestión de la catástrofe le cedían el protagonismo mediático, lo que facilitó la comunicación a través de una única voz. Además, era la primera autoridad de la ciudad. En el caso de Gamonal, se acuerda que el portavoz de la crisis sea el portavoz del equipo de gobierno municipal. En una ciudad, la sociedad desea ver al máximo responsable; en este caso, a su alcalde. Por eso, a pesar de contar como portavoz con el concejal de obras, los

\footnotetext{
día, Viladecans, Santa Lucía, Mataró, Jerez de la Frontera, Marbella y Benidorm, a las Comunidades Autónomas de Cataluña, Navarra y Madrid, y los ministerios de Educación y del Interior.

${ }_{10}$ En nuestra investigación para el INAP, los casos estudiados con mayor profundidad para el relevamiento de la información sobre el portavoz en los casos de comunicación de crisis han sido: Ayuntamientos de Benidorm, Marbella, Manresa, Prat de Llobregat, Logroño, Gandía, Almendralejo, Laguna de Duero, Viladecams, Jerez de la Frontera, Granada, Alovera, Telde, Villareal, Alicante, Santa Lucía, Verín, Mataró, San Bartolomé de Tinajara; las Comunidades Autónomas de Castilla-La Mancha, Islas Baleares, Andalucía, Cataluña y Madrid, y los ministerios del Interior, Educación y Sanidad.
} 
medios no dejaron, en ningún momento, de buscar la voz del regidor municipal, lo que implica la aparición, inevitablemente, de dos portavoces en la comunicación. De hecho, los medios de comunicación nacionales ceden espacio en sus diarios a la voz del regidor municipal ${ }^{11}$.

Un ejemplo muy ilustrativo de indecisión y de confusión respecto al portavoz autorizado se observa en la crisis del secuestro del pequero vasco «Alakrana» en el Océano Índico (Losada y Zamora, 2011: 138). Otro ejemplo lo constituye el caso de la crisis del Ébola, en la cual los cambios de portavoz generaron cierto desconcierto social, tanto en los públicos internos como en los externos y en los stakeholders. El cambio de portavoz se llega a interpretar como una desautorización pública de la portavoz, la ministra Ana Mato. Mato, además, ya era objeto de duras críticas por sus implicaciones indirectas en la trama Gurtel y había voces que demandaban su cese, a lo que se unían los polémicos recortes en sanidad durante su gestión al frente del ministerio. En la segunda fase de la crisis se le atribuyó la portavocía a una dirigente (la vicepresidenta del gobierno, Soraya Sáenz de Santamaría) que, en cambio, disfrutaba de una de las mejores valoraciones públicas de entre los miembros del gobierno, según las encuestas del CIS. Por ello, se asocia la resolución de la crisis con la intervención de la vicepresidenta como nueva portavoz con una mayor autoridad política.

\subsection{Relaciones con los medios}

Los medios de comunicación ocupan una posición privilegiada en el proceso político comunicativo de una crisis, «puesto que se convierten en actores pero también en vehículos, en transmisores, en instrumentos, en escenario; en definitiva, en jueces y parte. La política se juega, se desarrolla en los medios, pero a la vez su intervención resulta igualmente decisiva para decidir el resultado» (Redondo, 2010: 359). Las relaciones con los medios de comunicación requieren atenciones previas a la aparición de este fenómeno, estas relaciones se deben cultivar en tiempos de paz (Losada, 2010). Y en este cometido juega un papel relevante los directores de comunicación.

En seis de cada diez casos analizados no existen protocolos o manuales específicos destinados al trato con los medios de comunicación (Gráfico 13). En tres de cada cuatro ocasiones, en las que se establecen relaciones especiales con los medios de comunicación, el encargado de llevar a cabo dichas relaciones es el director de comunicación de la administración, siendo en el resto de los casos una función llevada a cabo por el portavoz o diferentes intervinientes del diseño de la comunicación de la administración.

GRÁFICO 13. PROTOCOLOS Y MANUALES DE RELACIONES CON LOS MEDIOS EN LAS ADMINISTRACIONES PÚBLICAS ¿Existen en su organización protocolos y manuales para las relaciones con la prensa?

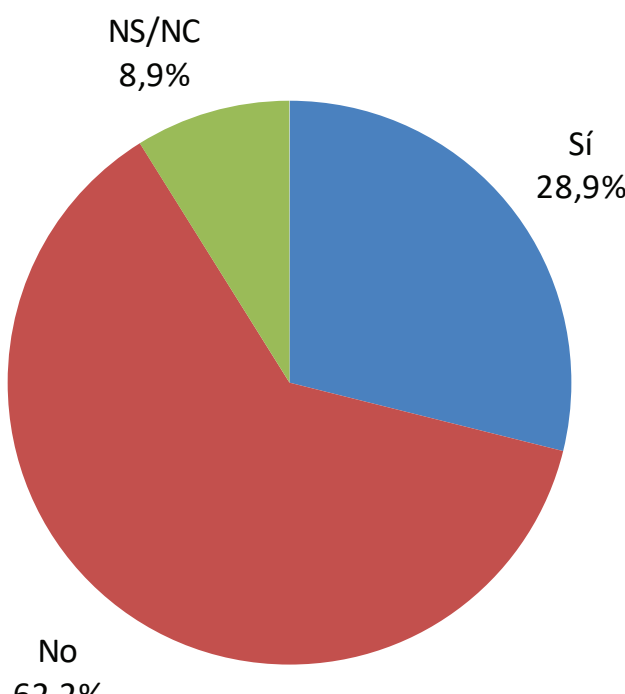

$\mathrm{N}: 45$ casos

11 Las tres ruedas de prensa que ofrece el alcalde de Burgos tienen más protagonismo mediático que las comparecencias del portavoz designado para la crisis. Estas ruedas de prensa son las del día 12, 14 y 17 de enero de 2014. En la primera se anuncia que las obras continúan a pesar de los actos violentos. En la segunda se comunica la paralización temporal, que no se hace definitiva hasta el día 17 de enero, este día tiene lugar la última comparecencia del primer edil de la ciudad. 
Un aspecto relevante, no contemplado en los cuestionarios realizados, pero cuya importancia han mostrado los estudios de caso, es el dilema entre la centralización o la descentralización del proceso comunicativo y las relaciones, no sólo con los medios de comunicación, sino con los equipos de comunicación de crisis de otros departamentos ministeriales o consejerías o de distintas administraciones públicas, en los casos en los que las competencias son compartidas o concurrentes (Boin y t'Hart, 2012).

En el análisis que realizan Boin, Hart, Stern y Sundelius (2007: 77), se sugiere que «apostar por la centralización en momentos de crisis puede ser una desventaja potencial», argumentando que el nivel de mayor autoridad, generalmente, no es el más competente técnicamente para tomar decisiones. Sin embargo, la experiencia práctica en el caso del Reino Unido y de España parece contradecir esta recomendación, especialmente en el ámbito comunicativo.

En el Reino Unido, en el otoño de 2000 , estalló una grave crisis por la subida del precio de los carburantes que, prácticamente, llegó a paralizar el país y pocos meses después, en febrero de 2001, estalló uno de los peores brotes de «fiebre aftosa» en Europa. En ambos casos, la estrategia del gobierno Blair para gestionar la crisis fue similar: centralizar la toma de decisiones, lo que implicaba desplegar distintas tácticas con ese fin, como unificar la estructura de mando decisional o las comunicaciones, para que las acciones y los mensajes fueran coherentes. Como señaló Campbell (2015: 332-333), en ambos casos «la centralización demostró ser la respuesta» y "fue sólo cuando todo fue unificado en una estructura de mando que la marea comenzó a cesar. Esta estructura de mando única también significaba que todos daban mensajes consistentes. No hay nada peor en una crisis que gente diferente expresando diferentes relatos y excusas - estas respuestas descoordinadas erosionan tanto la efectividad como la confianza».

En España el mejor ejemplo reciente es el caso del Ébola, en el que se aprecia una notable cooperación entre las administraciones autonómica y central, ambas presentes en la mesa del comité de crisis que dirigía la ministra Ana Mato, pero en el que se produjeron ciertas deficiencias en la interadministrativa o interinstitucional de la comunicación: las intervenciones del entonces consejero de Sanidad de Madrid provocaron algunas reacciones que eclipsaron la gestión del gobierno central, en especial por unas desafortunadas declaraciones que distrajeron la atención de lo fundamental y ocuparon gran parte de las portadas de prensa y de los titulares en los noticiarios de los medios de comunicación. Cualquier acción del gobierno central o del ministerio de sanidad, por adecuada que pudiera ser, no se apreció, debido a este ruido mediático y desplazó el interés de la ciudadanía y de los medios hacía estas declaraciones ${ }^{12}$. Sin duda, la lección de esta experiencia es que conviene en las crisis sanitarias proceder a una centralización de la comunicación, una estrategia que acabó prevaleciendo en la crisis del Ébola, y que, en casos previos, también había mostrado su eficacia, como en el caso de la gripe A en 2009.

\subsection{El mensaje: elementos y herramientas}

El mensaje presenta una serie de características especiales cuando se trata de una crisis. Por ello, las herramientas o elementos que se utilizan para reforzar el mensaje se adaptan o enfatizan de forma especial. La anticipación de mensajes a otros actores involucrados en la crisis, la adaptación de los mensajes a las distintas herramientas comunicativas, las medidas destinadas a reducir la incertidumbre y la confusión, así como la adaptación del mensaje a cada grupo de interés, son elementos destacados en los casos analizados (Gráfico 14). La estrategia de comunicación de una crisis debe apostar por un mensaje fácil de entender por todos los públicos, esta «necesidad de dar explicaciones sencillas a fenómenos complejos no es solamente un axioma de la comunicación en caso de crisis, es la base de cualquier tipo de comunicación» (Elizalde, Fernández y Riorda, 2011: 24).

Una circunstancia adicional, no explorada en el cuestionario, pero que han revelado los estudios de caso es la relevancia del cierre de la crisis para la percepción de la gestión de la comunicación de la misma por la opinión pública. En este aspecto, hay que diferenciar, además, las dos dimensiones del cierre de la crisis: el cierre político y el cierre operacional de la misma. El final de la crisis se produce, precisamente, cuando se ha conseguido el cierre en ambas dimensiones. Desde la perspectiva operativa, este proceso concluye cuando el estado de emergencia, la infraestructura de respuesta y la movilización de recursos que

12 Algunos ejemplos de declaraciones del Consejero de Sanidad de la Comunidad Madrid en el caso Ébola: «Para explicar a uno cómo quitarse o ponerse un traje no hace falta un máster»; «Ha tardado días en reconocer que pudo tener un fallo al quitarse el traje. Si lo hubiese dicho ante habríamos ahorrado mucho trabajo»; «Tan mal no debía estar para ir a la peluquería»; "Si lo hubiese hecho tan mal -Teresa Romero- no estaría hablando». 
se han desplegado ya no se consideran necesarios. El cierre político implica un final simbólico y público de la misma, expresado ante los medios de comunicación y aceptado por la opinión pública.

\section{GRÁFICO 14. MENSAJES PREVISTOS EN LAS ADMINISTRACIONES PÚbLICAS EN SITUACIONES DE CRISIS. ¿QUÉ ELEMENTOS Y HERRAMIENTAS, RELACIONADAS CON EL MENSAJE EN SITUACIONES DE CRISIS, ESTÁN PREVISTOS EN SU ORGANIZACIÓN?}

Adaptación de los mensajes a las distintas herramientas comunicativas

Medidas para la reducción de la confusión

Medidas para la reducción de la incertidumbre relacionada con la crisis

Anticipación de los mensajes a los de otros actores

Adaptación del mensaje a cada grupo de interés

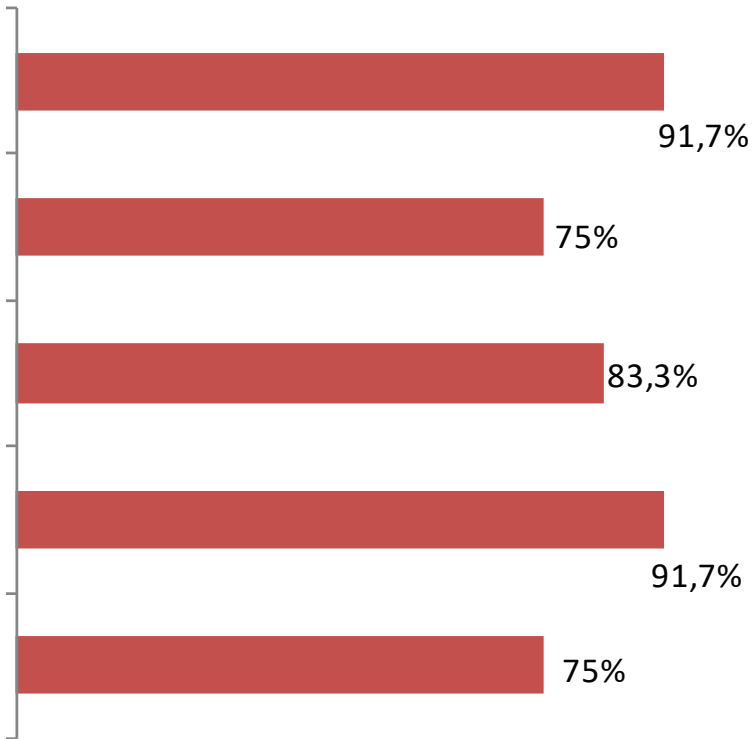

Esta dualidad, sin embargo, crea la posibilidad de desajustes entre ambos momentos de cierre, puesto que se puede producir una simultaneidad entre ellos, como en las crisis de Lorca y de los controladores aéreos, o bien un desajuste y una secuenciación temporal de los mismos. Así, en las crisis sanitarias, como la del Ébola o la de la gripe A, sus cierres políticos son previos al cierre operativo, puesto que, una vez dada por clausurada la alerta correspondiente ante la opinión pública, los protocolos de salud exigen esperar determinados periodos de tiempo para descartar la reproducción de la enfermedad. En cambio, en otras crisis, como la del Prestige, el metro de Valencia o el Madrid Arena, el cierre operativo antecede al cierre político, en la medida en que la protesta organizada de los afectados y la exigencia de responsabilidades judiciales mantiene abierto el proceso político derivado de la crisis.

TABLA 4. CUATRO ESTADOS TÍPICO-IDEALES DE CIERRE DE CRISIS

\begin{tabular}{l|c|l|l}
\hline \multicolumn{4}{c}{ Cierre político } \\
\hline \multirow{3}{*}{ Cierre operacional } & Sí & $\begin{array}{l}\text { Terremoto de Lorca. } \\
\text { Crisis de controladores aéreos. }\end{array}$ & $\begin{array}{l}\text { Crisis del Prestige. } \\
\text { Metro de Valencia. } \\
\text { Madrid Arena. }\end{array}$ \\
\cline { 2 - 4 } & No & $\begin{array}{l}\text { Ébola. } \\
\text { Gripe A. }\end{array}$ & Atentados del 11-M. \\
\hline
\end{tabular}

Fuente: Adaptado a partir de Boin, Hart, Stern, Sundelius (2007: 123)

De estos desajustes entre el cierre político y el cierre operativo de las crisis surgen, además, dos «déficit de manejo del tiempo» (Boin, Hart, Stern, Sundelius, 2007: 123-124): en primer lugar, la clausura prematura de las crisis, cuando los dirigentes públicos «subestiman la complejidad y la tenacidad de los problemas en cuestión, o malinterpretan el nivel de tensión residual existente en la comunidad afectada»; en segundo lugar, la extensión excesiva de las crisis, que suele acaecer cuando los líderes políticos se centran «tanto en la dimensión operacional de la crisis que pierden de vista el concepto general», lo que se ha venido a denominar la miopía del «síndrome del búnker», una situación de cierto autismo o aislamiento decisional 
en el que los funcionarios y directivos «se sientan en un centro de mando durante semanas enteras, desde donde gestionan la crisis y se ensimisman en flujos de comunicación aparentemente urgentes» mientras «el mundo exterior sigue adelante hacia otras preocupaciones». En este sentido, como han señalado destacados expertos en crisis políticas, como Linz (2006: 84-86), lo adecuado es que la decisión sobre el cierre de la crisis sea tempestiva y, en ningún caso, ni prematura ni diferida.

\section{POST-CRISIS: EVALUACIÓN Y CULTURA DE CRISIS}

La terminación de la crisis inaugura la fase de post-crisis, que es cuando el interés mediático traslada su foco de atención a otro aspecto noticiable y desde la organización se emprende la evaluación de la estrategia de comunicación. La crisis constituye una oportunidad de superación, pero para eso es preciso emprender un balance sobre errores y aciertos cometidos en la gestión de la crisis, que permita incorporar los aciertos a planes que contengan la aparición de nuevas crisis. En este sentido se pronuncian Vanaclocha, García y Natera cuando se refieren a las lecciones aprendidas, que al finalizar una crisis proporcionan «un feed-back a la prevención así como a la planificación y respuesta» (Vanaclocha, García y Natera, 2010: 242).

Los resultados de este estudio revelan la escasa importancia que las administraciones confieren a la evaluación de la gestión de crisis. De las 75 unidades que constituyen la muestra, tan solo 12 administraciones elaboran un documento de lecciones aprendidas que puede servir para mejorar la gestión de la comunicación ante futuras crisis.

En cuanto a las herramientas empleadas para crear y promover la cultura de la gestión de crisis, destaca la concienciación de los responsables (y también del conjunto de los trabajadores) sobre la importancia de la crisis: esta relevancia es subrayada por el $82,1 \%$ de los directivos y responsables públicos (sólo niega que exista dicha concienciación el $7,7 \%$ ) y por el $53,8 \%$ de los empleados públicos (por su parte, el $28,2 \%$ de los mismos niega que exista esta concienciación). En un segundo plano quedaría la formación, tanto de directivos como de trabajadores, en materia de crisis (Gráfico 15).

\section{GRÁFICO 15. INSTRUMENTOS PARA LA CREACIÓN DE UNA CULTURA DE GESTIÓN Y COMUNICACIÓN DE CRISIS EN LAS ADMINISTRACIONES PÚBLICAS. ¿QUÉ HERRAMIENTAS EMPLEAN SU ORGANIZACIÓN COMO MEDIDAS PARA LA CREACIÓN Y PROMOCIÓN DE UNA CULTURA DE GESTIÓN DE CRISIS?}

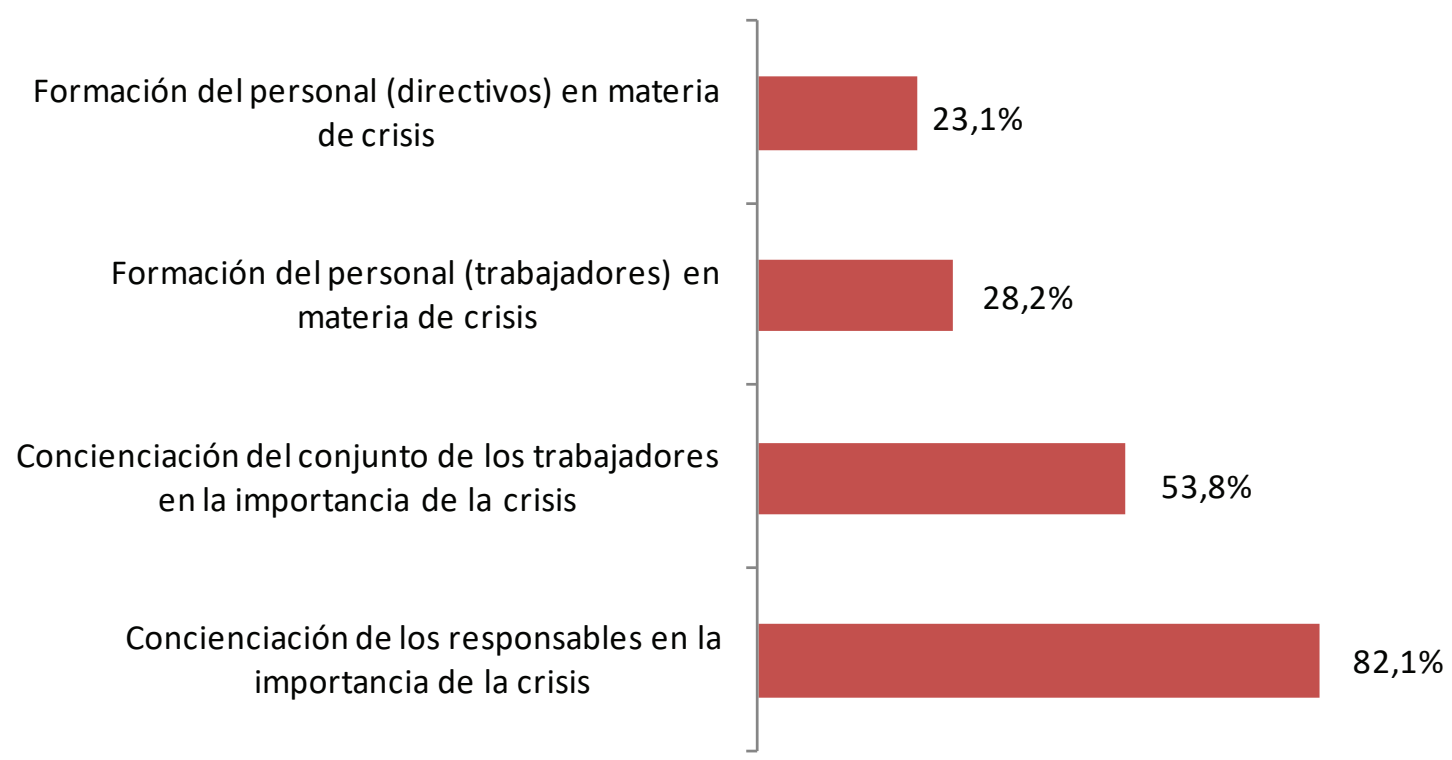

Los elementos de transparencia contemplados en la mayoría de las organizaciones, destinados para ser empleados en situaciones de crisis, son el envío de mensajes periódicos para la actualización de la información, la publicación de dosieres y documentos que refuercen el mensaje emitido, o medidas de atención a afectados, como ventanilla única, teléfono de contacto e indicaciones para el contacto y accesibilidad con los actores (Gráfico 16). 
GRÁFICO 16. TRANSPARENCIA EN LAS ADMINISTRACIONES PÚBLICAS PARA SITUACIONES DE CRISIS. ¿QUÉ ELEMENTOS DE TRANSPARENCIA CONTEMPLA SU ORGANIZACIÓN EN SITUACIONES DE CRISIS?

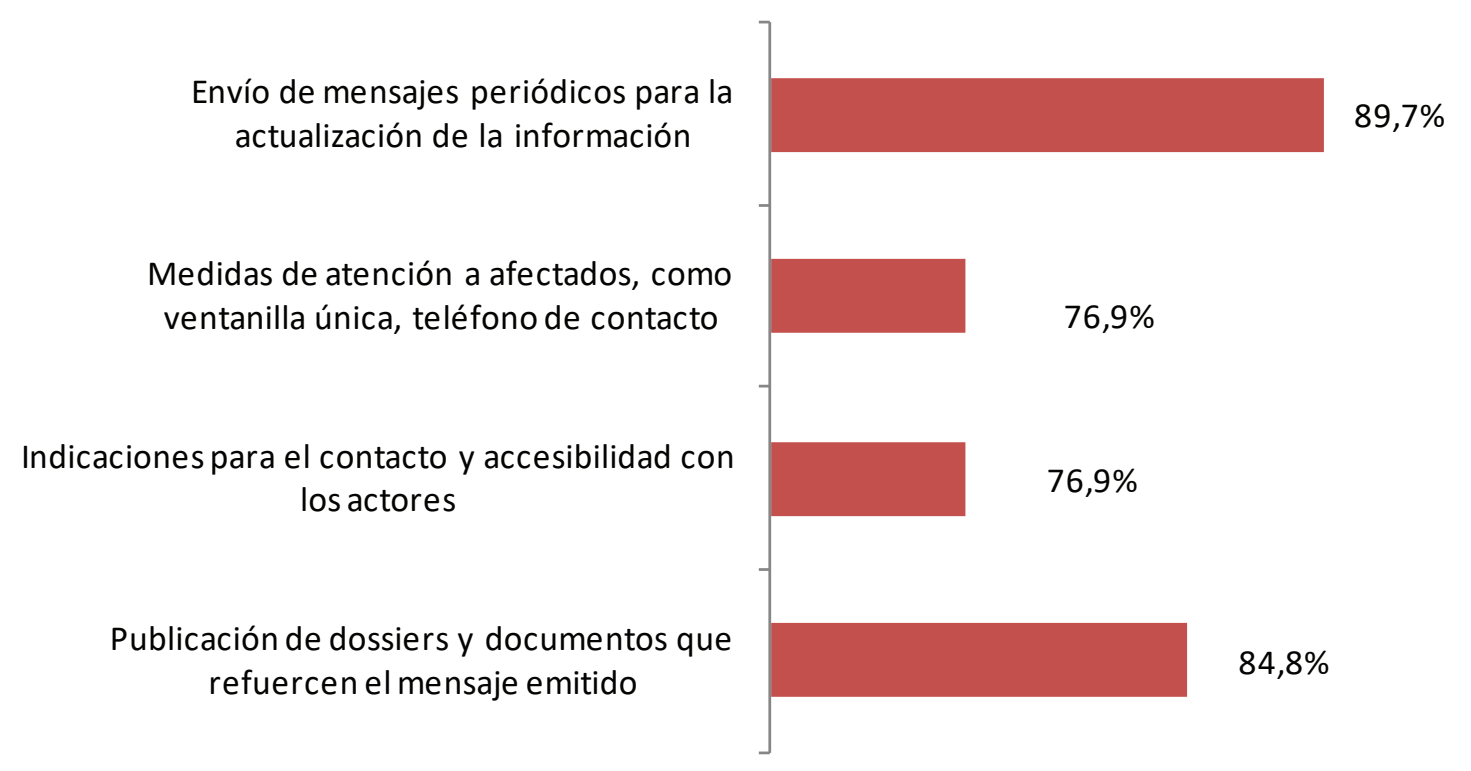

\section{DISCUSIÓN DE LOS RESULTADOS}

Los resultados obtenidos arrojan datos significativos sobre el gran déficit que arrastran las administraciones públicas españolas en materia de gestión y comunicación de crisis. En primer lugar, el ámbito territorial de la administración condiciona la respuesta en la preparación y en las medidas de gestión de la comunicación de crisis: conforme aumenta el nivel de actuación de la administración, se aprecia una mayor preparación e implementación de una política de comunicación de crisis. En segundo lugar, la situación real confirma que las administraciones públicas no están suficientemente preparadas para afrontar situaciones de crisis. Quizás la rigidez del procedimiento administrativo entre en colisión con la necesaria urgencia y rapidez en las actuaciones para hacer frente a estas circunstancias excepcionales y, a veces, únicas. Esta situación es especialmente evidente en la Administración local, donde además se suma el déficit en profesionales especializados en resolución y comunicación de crisis. Por último, del análisis de resultados de la investigación realizada en las distintas administraciones públicas españolas que configuran el núcleo central de la investigación encargada por el INAP, podemos destacar los siguientes resultados:

Uno. Existe un desconocimiento del significado y alcance de la comunicación de crisis. Esta situación explica, especialmente, por qué no están preparadas la mayoría de las Administraciones para gestionar una situación de crisis de modo previo. La primera conclusión que resulta importante destacar es que apenas seis de cada diez administraciones públicas tienen prevista la gestión de la comunicación en situaciones de crisis, lo que representa una cifra verdaderamente reducida. En cerca del $90 \%$ de aquellas administraciones donde se gestiona la comunicación de crisis, es el departamento de comunicación el encargado de dicha tarea, recayendo dicha responsabilidad en el director de comunicación, en más del $65 \%$ de las ocasiones.

Dos. Hay una evidente falta de medios. Los responsables de la Administración local aseguran no disponer de los medios para poder desarrollar una adecuada planificación de la gestión y comunicación de crisis o entienden esta planificación como poco necesaria para su organización. Al ser entidades menores no son plenamente conscientes de que les vaya a suceder a ellos una situación de esta naturaleza y si les ocurre no son conscientes del grave perjuicio que les puede ocasionar en su imagen pública y en su reputación y credibilidad tanto institucional como organizativa.

Tres. Se manifiesta una escasa formación para afrontar las situaciones de crisis. El portavoz del comité de crisis coincide, por lo general, con la máxima autoridad, que no dispone, generalmente, de una formación adecuada y específica orientada hacia esta modalidad de comunicación. Resulta destacable, asimismo, que en tres de cada cuatro ocasiones el responsable de la comunicación de crisis mantiene una relación contrac- 
tual de personal de confianza, lo que puede implicar, en cierta manera, la falta de continuidad de la gestión, pues se presenta asociada a la permanencia del líder político coyuntural.

Cuatro. La comunicación de las organizaciones es principalmente reactiva. Son muy escasas las administraciones públicas que dispongan, sin haber experimentado este tipo de situaciones previamente, de un comité de crisis, donde se identifiquen y delimiten las funciones atribuidas a sus miembros, así como el perfil que debe cumplir cada uno de sus integrantes. Además, cerca de tres de cada cuatro instituciones consultadas no realiza auditorías de crisis y, entre aquellas que las realizan, apenas en un tercio de las ocasiones dicha auditoría desciende a nivel de departamento. Por otro lado, casi en el $80 \%$ de las ocasiones tampoco se realizan simulacros de crisis.

Cinco. Hay limitaciones presupuestarias. La gestión de la comunicación de crisis se entiende como una parte más de la gestión de la comunicación en la organización, sin un presupuesto propio. Por tanto, la investigación realizada revela la ausencia de dotaciones presupuestarias para afrontar de modo proactivo la gestión de las crisis e incluso para afrontar los problemas derivados de una crisis de un modo más reactivo. La pauta más habitual es la existencia de una asignación genérica para la oficina de comunicación prevista para afrontar los clásicos gastos en publicidad y comunicación institucional.

Seis. La planificación no está documentada. El número de administraciones públicas que no disponen de un manual de comunicación en situaciones de crisis supera a las que cuentan con este instrumento. Resulta muy significativo que más de la mitad de las instituciones públicas que afirman gestionar la comunicación de crisis ni siquiera disponga de un comité de crisis. Tampoco existe en más del $60 \%$ de los casos un protocolo especial para la relación con los medios de comunicación en situaciones de crisis.

Siete. Hay una percepción muy extendida de una escasa probabilidad del surgimiento de una crisis. Las administraciones públicas conciben las crisis como situaciones muy esporádicas que raramente les sucede a ellas, razón por la que no entienden que este sea un tema prioritario. Las constantes demandas rutinarias de las organizaciones públicas y el propio funcionamiento diario hace difícil, a veces, dedicarse a la previsión y definición de escenarios y al desarrollo de instrumentos para afrontar futuras crisis.

\section{ANEXO 1. FICHA TÉCNICA DE LA ENCUESTA}

- Ámbito: España.

- Método de administración: cuestionario online auto administrado.

- Muestra diseñada: 130 instituciones de la Administración Pública Española, compuesta por responsables de la comunicación de los trece Ministerios, Gabinetes de comunicación de las Consejerías de Presidencia de las diecisiete Comunidades Autónomas, y cien Ayuntamientos. La selección de los Ayuntamientos sigue el procedimiento de afijación proporcional al tamaño de la provincia, y en el interior de la provincia selección de las unidades con mayor población.

- Muestra obtenida: 75 instituciones de la Administración Pública, conformada por 62 de la Administración local y regional, diez de la Administración Autonómica, y 3 de la Administración General del Estado (Ministerios).En definitiva, se consiguió abarcar el $50 \%$ de la muestra inicialmente prevista.

- Trabajo de campo: los datos fueron recopilados entre el doce de diciembre de 2015 y el veintinueve de abril de 2016.

\section{BIBLIOGRAFÍA}

BOHN, M. K. (2015), Presidents in crisis: Tough decisions inside the White House from Truman to Obama. Nueva York: Arcade Pub.

BOIN, A. y T'HART, P. (2001), "Between crisis and normalcy: The long shadow of pot-crisis politics", en ROSENTHAL, U.; BOIN, A. y COMFORT, L. K., eds., Managing crises. Threats, Dilemmas, Opportunities. Springfield: Charles C. Thomas.

BOIN, A. y T'HART, P. (2012), "Aligning Executive Action in Times of Adversity: The Politics of Crisis Coordination". En LODGE, M. y WEGRICH, K., eds. Executive Politics in Times of Crisis. Houndmills: Palgrave.

BOIN, A.; T'HART, P.; STERN, E. y SUNDELIUS, B. (2007), La política de la gestión de crisis. El liderazgo público bajo presión. Madrid: Instituto Nacional de Administración Pública (INAP).

BRÄNDSTRÖM, A. y KUIPERS, S. (2003), "From «normal incidents» to political crises: Understanding the selective politicization of policy failures", Government and Opposition, 38: 279-305. 
GAPP. Nueva Época - N. 18, noviembre 2017 - ISSN: 1989-8991 - DOI: 10.24965/gapp.v0i18.10465 - [Págs. 110-134]

La comunicación de crisis en la administración pública española: análisis de evidencia empírica Ismael Crespo / Antonio Garrido / Rosa M. a Medina

CAMPBELL, A. (2015), Winners: And How They Succeed. Londres: Hutchinson.

CANEL, M. J. (2010), Comunicación de las instituciones públicas. Madrid: Tecnos.

CASES, J. I., ed. (2010), Catástrofes medioambientales. La reacción social y política. Valencia: Tirant Lo Blanch. DOI: 10.4067/S0718-65682011000200021.

COOMBS, W. T. y HOLLADAY, S. J., eds. (2010), The Handbook of Crisis Communication. Wiley-Blackwell. DOI: $10.1002 / 9781444314885$.

CRESPO, I; GARRIDO, A.; CARLETTA, I. y RIORDA, M. (2011), Manual de comunicación política y estrategias de campaña: candidatos, medios y electores en una nueva era, Buenos Aires, Biblos.

CRESPO, I.; D'ADAMO, A.; GARCÍA BEAUDOUX, V. y MORA RODRÍGUEZ, A., eds. (2016), Diccionario Enciclopedico de Comunicación Política, 2. ${ }^{a}$ edición, Madrid: Centro de Estudios Políticos y Constitucionales.

CRUZ, J. (2004), La crisis y su influencia en las estrategias de comunicación organizacional [tesis doctoral]. Facultad de Ciències de la Comunicaciò, Universitat Autònoma de Barcelona.

DADER, J. L. (2004), "Comunipólogos: los sastres del emperador, sus hilos de oro y las lentes del público", en Revista Doxa, 2, págs. 191-215.

DRENNAN, L. T. y MCCONNELL, A. (2007), Risk and Crisis Management in the Public Sector. Nueva York: Routledge.

ELIZALDE, L. (2009), Gestión de Comunicación Pública. Empresas, Grupos e Instituciones en el escenario público. Barcelona: Bosch.

ELIZALDE, L., FERNÁNDEZ, D. y M. RIORDA (2011), La gestión del disenso. La comunicación gubernamemtal en problemas. Buenos Aires: La Crujía.

FEARN-BANKS, K. (2007), Crisis Communications. A Casebook Approach, 3. a edición. Londres: Lawrence Erlbaum As. Pub.

FREIJEIRO, M. (2010), "La gestión política en tiempo de crisis: un análisis de la actuación de los agentes públicos en el caso Prestige", en CASES, J. I. (comp.), Catástrofes medioambientales. La reacción social y política. Valencia: Tirant Lo Blanch.

FOX-GOTHAM, K. y GREENBERG, M. (2014), Crisis cities. Disaster and Redevelopment in New York and New Orleans. Oxford: Oxford University Press. DOI: 10.1093/acprof:oso/9780199752225.001.0001.

GARRIDO, A. (2016), "Comunicación política y opinión pública”. En BARREDA DÍEZ, M. y RUIZ RODRÍGUEZ, L. M., eds., El análisis de la política: Enfoques y herramientas de la ciencia política. Barcelona: Huygens.

GEORGE, A. M. y PRATT, C. B. (2012), Case Studies in Crisis Communication. International Perspectives on Hits and Misses. Nueva York: Routledge. DOI: 10.4324/9780203190661.

GERVÁS, J.; HERNÁNDEZ-AGUADO, I. et al. (2009), "Aciertos y errores en la gestión de las crisis de salud pública en España”, Gaceta Sanitaria, 23 (1): 67-71. DOI: 10.1016/j.gaceta.2007.11.001.

GONZÁLEZ HERRERO, A. (1998), Marketing Preventivo: La comunicación de crisis en la empresa. Barcelona: Bosch.

GUNDEL, S. (2005), "Towards a New Typology of Crises", en Journal of Contingencies and Crisis Management, 13 (3): 106-115. DOI: 10.1111/j.1468-5973.2005.00465.x.

HEAT, R. L. y O'HAIR, H. D., eds. (2009), Handbook of Risk and Crisis Communication. Nueva York: Routledge.

ISLAS, O. y HERNÁNDEZ, G., eds. (2013), Investigando la comunicación en crisis. México D. F.: Razón y Palabra.

LAGADEC, P. (1997), "Learning processes for crisis management in complex organiztions", en Journal of contingencies and crisis management, 5 (1), págs. 24-31.

LINZ, J. J. (2006), Robert Michels, political sociology and the future of democracy. New Brunswick, N. J.: Transaction Pub.

LOSADA, J. C. (2010), Comunicación en la gestión de crisis. Lecciones prácticas. Barcelona: UOC.

LOSADA DÍAZ, J. C. y ZAMORA MEDINA, R. (2011), "Gestión de la comunicación de crisis en secuestros: lecciones desde el «caso Alakrana»", Trípodos, 28: 129-142.

LOSADA MAESTRE, R. (2016), "Comunicación en situaciones de crisis", en SÁNCHEZ MEDERO, R., ed., Comunicación política. Nuevas dinámicas y ciudanía permanente. Madrid: Tecnos.

MAAREK, P. (2011), Campaign Communication and Political Marketing, Chichester: Wiley-Blackwell.

MAZZOLENI, P. (2004), La comunicazione politica, Bolonia, II Mulino.

MERCADO, M. T. y CHÁVEZ, M., eds., (2016), La comunicación en situaciones de riesgo y crisis. Valencia: Tirant lo Blanch.

MITROFF, I. I y PEARSON, C. M. (1997), Cómo gestionar una crisis. Barcelona: Gestión 2000.

OLMEDA, J. A. (2010), "Gestión de crisis, rendición de cuentas y aprendizaje", en ARENILLA, M., ed., La administración pública entre dos siglos (Ciencia de la Administración, Ciencia Política y Derecho Administrativo). Madrid: INAP

OLSSON, E. K. (2014), "Crisis Communication in Public Organisations: Dimensions of Crisis Communication Revisited", en Journal of Contingencies and Crisis Management, 22 (2): 113-125. DOI: 10.1111/1468-5973.12047.

PANIAGUA, C. (2010) "Una historia de la comunicación de crisis en España”, en Revista Icono14, 8 (2), págs. 3-24. DOI: 10.7195/ri14.v8i2.243.

PIÑUEL, J. L. (1997), Teoría de la comunicación y gestión de las organizaciones. Madrid: Síntesis.

REDONDO, J. (2010), "Estrategias de comunicación en tiempo de crisis: los mensajes del gobierno a través de los medios tras el hundimiento del Prestige", en CASES, J. I. (comp.), Catástrofes medioambientales. La reacción social y política. Valencia: Tirant Lo Blanch. 
RIORDA, M. (2011), "Gestionando certidumbres: la comunicación de crisis no es comunicación gubernamental, electoral ni de riesgo", en ELIZALDE, L.; FERNÁNDEZ, D. y RIORDA, M., eds., La gestión del disenso. La comunicación gubernamental en problemas. Buenos Aires: La Crujia.

RIORDA, M. (2016), "Comunicación de crisis", en CRESPO, I.; D'ADAMO, A.; GARCÍA BEAUDOUX, V. y MORA RODRÍGUEZ, A., eds., Diccionario Enciclopedico de Comunicación Política. Madrid: Centro de Estudios Políticos y Constitucionales.

ROSENTHAL, U.; BOIN, A. y COMFORT, L., eds. (2001), Managing crises. Threats, dilemmas, opportunities. Springfield, III.: Charles C. Thomas.

ROSENTHAL, U.; M. CHARLES, M. y T'HART, P., eds. (1989), Coping with crisis: The management of disasters, riots and terrorism. Springfiel, III. Charles C. Thomas.

TUÑEZ, M. (2005), Informar en crisis. Proactivos desde la veracidad, en Gestión informativa de crisis en catástrofes marítima. Xunta de Galicia. La Coruña: Fundación Santiago Rey Fernández-Latorre.

VALE, L. J. y CAMPANELLA, T. J., eds. (2005), The resilient city. How modern cities recover from disaster. Oxford: Oxford University Press.

VANACLOCHA, F. J., NATERA, A. y GARCÍA SÁNCHEZ, E. (2007), "Prestige y 11-M: la vertebración política de la gestión de catástrofes", Universidad Carlos III de Madrid, Departamento de Ciencia Política y Sociología, Documentos de Trabajo/Política y Gestión, núm. 11.

VANACLOCHA, F. J., GARCÍA SÁNCHEZ, E. y NATERA, A. (2010), "La evaluación de la gestión de crisis: dimensiones analíticas y criterios de valor", en Cases, J. I. (comp.), Catástrofes medioambientales. La reacción social y política. Valencia: Tirant Lo Blanch.

WESTPHALEN, M. H., y PIÑUEL, J. L. (1993), La dirección de Comunicación: Prácticas profesionales, diccionario técnico. Madrid: Ediciones del Prado. 